\title{
Mapeamento das pesquisas e publicações brasileiras vinculadas a rede internacional de escolas criativas
}

\author{
Nayhara Gomes da Silva * \\ Marilza Vanessa Rosa Suanno **
}

\section{Resumo}

O presente artigo tem por finalidade produzir um mapeamento das pesquisas e publicações brasileiras que estão vinculados a Rede Internacional de Escolas Criativas - RIEC. O objetivo do trabalho é divulgar o crescimento da rede a partir de publicações vinculadas a mesma, a metodologia usada para elaboração do trabalho envolveu pesquisas bibliográficas em livros, artigos e sites ligados ao RIEC, a rede tem por finalidade analisar e reconhecer escolas e projetos criativos com visões criativas, transformadoras e inovadoras, para Torre (2012) as escolas devem contribuir para um clima de inovação, trazendo para escola práticas criativas, desta forma contribuindo para a formação de discentes criativos.

Palavras-chaves: RIEC, escola, criatividade, ecoformação.

Mapping research and Brazilian publications linked international to network of creative schools

\begin{abstract}
This article aims to produce a mapping of research and Brazilian publications that are linked to International Schools Network creation tives - RIEC. The objective is to promote the growth of the network from publications linked to it, the methodology used to prepare the work involved bibliographic research in books, articles and websites linked to RIEC, the network has intended to analyze and recognize schools and creative projects with creative visions, transformative and innovative for Tower (2012) schools should contribute to a climate of innovation, bringing to school creative practices, thus contributing for the training of creative students.
\end{abstract}

\footnotetext{
Licenciada em Pedagogia (Faculdade Padrão/2011). Especialista pelo Programa de Pós-Graduação em Transdisciplinaridade e Interdisciplinaridade na Educação, Universidade Estadual de Goiás, Câmpus Inhumas.E-mail: nayharagomes@hotmail.com

** Orientadora. Doutora pelo Programa de Pós-Graduação em Educação da Universidade Católica de Brasília - UCB (2015). Mestre em Educação pela Pontifícia Universidade Católica de Goiás, Brasil (2006). Pedagoga pela Universidade Federal de Goiás, Brasil. E-mail: marilzasuanno@uol.om.br
} 
Keywords: RIEC. School. Creativity. Eco-Formation.

Introdução

Este artigo tem por finalidade reunir, tabular e atualizar os dados referentes as produções acadêmicas da Rede Internacional de Escolas Criativas - RIEC no Brasil, com o intuito dar visibilidade a sistematização das pesquisas desenvolvidas e das escolas criativas identificadas entre 2012 e 2015. Para tal foram pesquisadas as equipes:

a) RIEC/UFT coordenada pela Profa. Dra. Maria José de Pinho na Universidade Federal do Tocantins; b) RIEC/FURB coordenada pela Profa. Dra. Vera Lúcia de Souza e Silva na Universidade Regional de Blumenau; c) RIEC/Sul do Estado de Santa Catarina coordenada pela Profa. Dra. Marlene Zwierewicz - UNIBAVE; d) RIEC/ UNIVALI coordenada pela Profa. Dra. Maria Glória Dittrich; e) RIEC/UECE coordenada pela Profa. Dra. Patrícia Limaverde; f) RIEC/UEG coordenado pelo Prof. Dr. João Henrique Suanno e Profa. Dra. Marilza Vanessa Rosa Suanno.

A Rede Internacional de Escolas Criativas - RIEC foi criada durante o IV Fórum Internacional sobre Inovação e criatividade: adversidade e escolas criativas - INCREA, realizado na Universidade de Barcelona, em junho de 2012. O objetivo da RIEC é reconhecer os potenciais das escolas que tem visões transformadoras, inovadoras e criativas tanto no âmbito educacional como no âmbito social.

A RIEC foi elaborada e impulsionada a partir da Ata de Criação (RIEC, 2012); da publicação do livro Instrumento para valorar el desarrollo creativo de las instituciones educativas - VADECRIE (TORRE, 2014); da corroboração deste instrumento de pesquisa por meio da tese de Doutorado em Educação, de João Henrique Suanno, essa orientada pela Profa. Dr. Maria Cândida Moraes, intitulada Escolas Criativas e Práticas Pedagógicas Transdisciplinares e Ecoformadoras (J. SUANNO, 2013) e por pesquisas desenvolvidas por membros da RIEC, que tem por principios: ecologia dos saberes, sustentabilidade, a ruptura com a lógica da fragmentação disciplinar do conhecimento e tem por base teórica o Decálogo sobre Transdisciplinaridade e Ecoformação (2008).

$\mathrm{O}$ intuito maior do RIEC é investigar e contribuir para o reconhecimento e socialização dos projetos pedagógicos de instituições educativas que tenham indícios de serem superadoras das próprias realidades, transcendendo a si mesma enquanto instituição.

escolas criativas as instituições educativas que criam, inovam, desenvolvem as potencialidades institucionais, humanas, sociais e ambientais em uma 
perspectiva complexa, transdisciplinar e ecoformadora. Desta forma, o conceito de escola criativa articula-se à transdisciplinaridade e à ecoformação. (SUANNO et al, 2014)

Apesar das mudanças ocorridas na sociedade, infelizmente a grande maioria das escolas não acompanharam esse desenvolvimento, pois continua ligada a forma de ensinar tradicionalista que não percebe o aluno como um ser pensante, capaz de criar e recriar seus aprendizados. Para Torre $(2014$, p. 2):

os sistemas educativos, as escolas e as práticas pedagógicas na atualidade têm limitações e destaca que dentre estes limites o fato das escolas continuarem priorizando os conteúdos e limitando-se em tal tarefa. As escolas mantêm currículos fechados, que ensinam conhecimentos fragmentados em disciplinas, desconectados da vida, das questões e dos problemas que afligem a contemporaneidade.

A escola deve ser um espaço para ampliar a criatividade humana, ou seja, tornar o ser humano, um ser pensante que é capaz de criar, mas esse método tradicional não permite ao aluno ser ver como um ser pensante capaz de criar, ele bloqueia, disciplina e inibe esse instinto pela criatividade. Todo ser humano é capaz de criar e inovar basta ter a oportunidade de pensar, problematizar e inovar e esses são os conceitos necessários para o futuro.

uma educação criativa deve oportunizar ao sujeito a construção de conhecimentos, o desenvolvimento pleno de sua inteligência, sensibilidade, corporeidade, autoconhecimento e consciência ampliada na relação humana, social e ambiental. (SUANNO et al ,2014)

As inspirações para os projetos criativos inovadores se baseiam no pensamento complexo e Transdisciplinaridade de Edgar Morin e também Basarab Nicolescu.

\section{Pensamento Complexo e Transdisciplinaridade}

O pensamento complexo é um conceito criado por Edgar Morin (1991) que busca conscientizar as pessoas para uma nova forma de se pensar a ciência, a educação e a sociedade. Tal modo evidencia a necessidade de ruptura ideológica com o modelo cartesiano que está em voga desde o século XVII. Assim, confronta-se com a fragmentação do conhecimento, do disciplinamento do ser, da certeza absoluta, dos métodos 
de ensino pautados na memorização, repetição entre outros mecanismos vistos com tradicionais que seguem ordens e hierarquias.

Morin (2000) conclama para esta necessidade de ruptura com a segregação do saber em detrimento do poder, revelando assim a necessidade de mudança de paradigmas, ou seja, precisa-se imediatamente de uma tomada de consciência para que os seres humanos possam repensar suas atitudes em relação aos seus pares, valorizando assim práticas de educação humanizadas. Para esta transformação o autor supracitado destacou a necessidade do pensamento complexo ligado às atitudes transdisciplinares. $\mathrm{Na}$ busca do conceito do que é transdisciplinaridade, Suanno (2013) destaca que:

A transdisciplinaridade caracteriza-se por ser uma pulsão religadora, por buscar pensar complexo, multidimensional, multirreferencial, articulando razão, emoção e atitude transformadora, trabalhando assim com uma razão sensível e práxis complexa e transdisciplinar. (SUANNO, 2013, p. 18)

Com base nos pressupostos referidos na citação, analisa-se que uma atitude transdisciplinar está intimamente relacionada com uma gama de conhecimentos crucias para sua realização. Na Obra: Os sete saberes necessários à educação do futuro, Morin (2000), traz fundamentações essenciais para a construção de uma nova práxis educativa baseada na cooperação, na valorização do sujeito em sua totalidade, na ressignificação do conhecimento e na necessidade de religar saberes, compreendendo que estes saberes são vistos como fundamentais para enfrentar os problemas que são complexos desta sociedade contemporânea.

Esses temas Pensamento Complexo e Transdisciplinaridade estão relacionados e foram abordados em importantes eventos científicos realizados pela UNESCO em Madrid (2009), Barcelona (2010) e Brasil (2010). O objetivo principal destes eventos concentrava em auxiliar na construção de orientações fundamentadas e para encontrar meios que levem a outras possibilidades educacionais visando a formação de alunos críticos e criativos.

As contribuições significativas do pensamento complexo é difundido no ideário de se criar um modelo pedagógico integral na perspectiva transdisciplinar, na busca de que os envolvidos nesse processo possam ter uma ampla consciência acerca da problemática educacional. Visa-se reestruturar a prática pedagógica no sentido de estimular a criatividade e a inovação, tanto de professores como alunos, para que ambos se adaptem aos desafios do mundo moderno.

Diferentemente da didática construída desde o século XVII que preconiza a individualidade, a disciplina por meio do autoritarismo e da relação professor-aluno em 
uma ordem vertical de aprendizagem, o pensamento complexo que valoriza atitudes significativas e restabelece as relações. O respeito a pluralidade cultural, a valorização de concepções e práticas pedagógicas criativas e inovadoras, a importância de uma consciência ecológica e o compromisso com a responsabilidade social e planetária são características fundamentais deste novo paradigma emergente.

A transdisciplinaridade entendida como uma proposta para educação é entendida por Suanno (2013) como "aquilo que está ao mesmo tempo entre as disciplinas, através das disciplinas [...] um princípio que associa as partes e o todo, por compreender que é impossível conhecer as partes sem conhecer o todo" (SUANNO, 2013, p.7), ou seja, o relacionamento entre os saberes científicos e saberes locais. Os sete saberes propostos por Morin (2000) são relevantes no sentido de proporcionar uma educação transformadora que emancipa o sujeito.

A realidade atual de nossa sociedade se reflete em um mundo bastante complexo, por isso há uma necessidade urgente do pensamento humano evoluir também, igualmente, as comunidades escolares devem acompanhar tal processo. Diante deste panorama, Santos (2003) destaca que:

O nosso modo de ensinar é incipiente frente à nova metáfora em rede do conhecimento. Não se aprende linearmente. A compreensão do significado de uma frase evoca instantaneamente imagens, sons, experiências vividas, intuições, sensações, humores, deduções, comparações, relações lógicas, analogias, rejeições, sentimento de cooperação ou solidariedade, coerência em relação à utopia ou conhecimentos de outras áreas, contexto individual, social, ético, estabelecendo assim, uma rede de articulações invisíveis para os que estão de fora. (SANTOS, 2003, p.11)

Percebe-se que a educação, nesta perspectiva, valoriza a articulação e a religação de conhecimentos, a complexidade (MORIN, 2000), ou seja, o que é tecido em conjunto. Uma educação e formação humana que reintroduz o sujeito cognoscente e valoriza o pensar complexo, a subjetividade, os conhecimentos historicamente sistematizados, os valores humanos, as atitudes éticas, dentre outros.

Morin (2000) revela as dificuldades de se discutir um novo modo de pensar a sociedade e a educação, pois, se encontra neste processo histórico a inteligência parcelada, compartimentada, mecanicista, disjuntiva e reducionista, na qual se fraciona os problemas, separa o que está unido, torna unidimensional o multidimensional. $\mathrm{Na}$ perspectiva da racionalidade, a partir da educação apoiada no processo de reforma do pensamento tem-se com a transdisciplinaridade a oportunidade da utilização de 
linguagens variadas, de outras possibilidades pedagógicas, de outros recursos, enfim, fazer do conflito uma oportunidade de aprendizagem.

\section{Ecoformação}

Escolas criativas têm investido esforços na ecoformação, um processo de formação continuada, coletivo, integrado, cooperativo, no contexto da própria escola, uma formação em exercício profissional, buscando juntos superar a si mesmo pelo esforço coletivo.

Ecoformação tem relação com as demandas da realidade atual, já que se vive uma emergência planetária, com enormes problemas relacionados entre si, tais como: a contaminação e degradação dos ecossistemas; o esgotamento de recursos naturais; o crescimento incontrolado da população mundial; conflitos bélicos atrozes e incompreensíveis em nosso grau de civilização; perda da diversidade biológica, linguística e cultural, tudo isso acrescentado a uma profunda crise econômica global que não parece ser uma educação comprometida com a vida. (MALLART, 2009, p. 29)

Podemos dizer que ecoformação é uma ação formativa que integra a relação entre o sujeito e o meio a qual está inserido e a escola tem um papel importante nessa ação formativa do sujeito e da sociedade em relação à sua interação com a natureza e os meios de realizar uma boa convivência com a natureza, que preserve tanto o bem -estar pessoal como também o social e sua relação com o ambiente. A ecoformação valoriza a relação humana, a transdisciplinaridade e a sustentabilidade.

o conceito de ecoformação requalifica a Educação Ambiental como Formação Humana Permanente. Do mesmo modo, amplia a dimensão teleológica da Educação Permanente na medida em que a entende não apenas como um processo educativo de formação para o trabalho, mas como um processo mediador da relação do homem com seu ambiente social e natural (SILVA, 2008, p. 97).

Ecoformar instruindo para um desenvolvimento sustentável e solidário, comprometido com o planeta e com todos seus habitantes, ou seja, é criar um cidadão consciente e ativo preocupado e solidário com o meio, não só o que se refere a natureza como também com a convivência e respeito com o outro. Uma escola que trabalha com a ecoformação promove em seus alunos a responsabilidade, a autonomia, o senti- 
do crítico, a capacidade de tomada de decisões, a busca de soluções e o favorecimento da criatividade.

Pesquisas da RIEC/Brasil

O grupo de pesquisa RIEC/Brasil está cadastrado no Conselho Nacional de Desenvolvimento Científico e Tecnológico - CNPq

Esta pesquisa buscou reunir e tabular as publicações dos grupos regionais de pesquisa da RIEC/Brasil. A equipe da Universidade Federal do Tocantins - UFT, coordenada pela Profa. Dra. Maria José de Pinho é composta por três alunos de iniciação cientifica, 8 mestrandos, 3 doutorandos e 1 graduando. Esta equipe já publicou 24 artigos completos publicados em periódicos; 3 livros publicados/organizados ou edições; 14 capítulos de livros; 22 trabalhos completos publicados em anais de congressos; 3 resumos expandidos publicados em anais de congressos e 5 outras produções bibliográficas. As pesquisas da equipe do Tocantins envolvem a formação de professores, nas áreas de língua portuguesa, língua inglesa e Pedagogia.

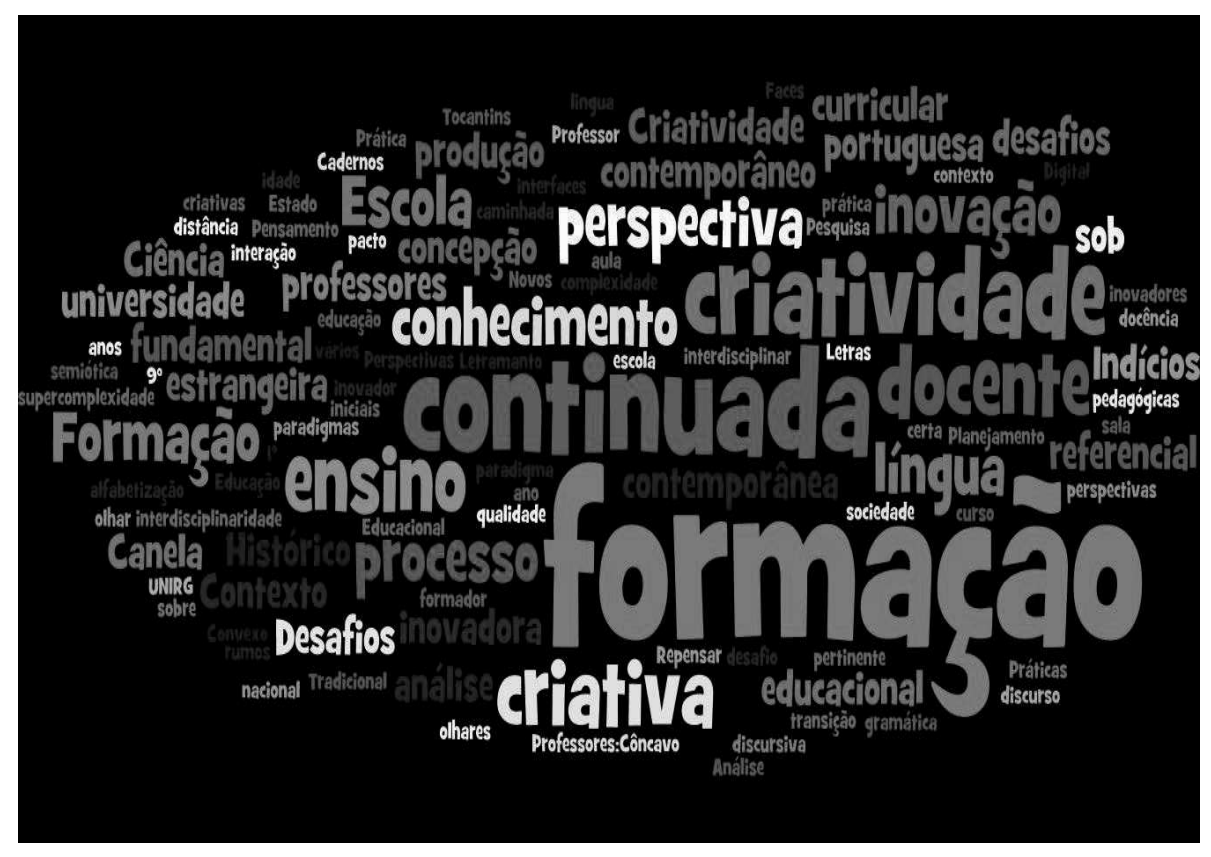




\section{ARTIGOS COMPLETOS PUBLICADOS EM PERIODICOS}

DUARTE, J. G.; PINHO, M.J. Uma análise sobre o referencial curricular de língua estrangeira do Estado do Tocantins sob a perspectiva da criatividade e interdisciplinaridade. Revista Leia Escola, v. 14, p. 127-139, 2015.

PINHO, M. J.; MORAIS, M.J.S. Criatividade na formação continuada docente nos anos iniciais do ensino fundamental: Perspectivas e desafios inovadores. Revista SODEBRAS, v. 10, p. 89-93, 2015.

PINHO, M.J.; MORAES, M.J.S. Prática criativa e inovadora no processo de formação continuada. Revista de Ciências Humanas, v. 15, p. 80-93, 2015.

PINHO, M.J.; MORAES, M.J.S.; SANTANA, Jocyléia. Indícios de criatividade e inovação no processo de formação continuada. Revista Ibero-Americana de Estudos em Educação, v. 9, p. 880, 2015.

DUARTE, J.G.; PINHO, M.J. Criatividade, gramática e interação no ensino de língua portuguesa. Revista Querubim, v. 1, p. 78-83, 2015.

PINHO, M.J.; DE QUEIROZ SOUZA, KÊNIA PAULINO. Ciência e produção do conhecimento contemporâneo na perspectiva da criatividade. Revista de Ciências Humanas (UFSC), v. 49, p. 2-16, 2015.

PINHO, M.J.; MORAES, M.J.S.; SANTANA, Jocyléia. Indícios de inovação e criatividade no processo de formação continuada. Conjectura: Filosofia e Educação (UCS), v. 20, p. 129-150, 2015.

PINHO, M. J.; BARROS, T. C. Práticas pedagógicas criativas: Um olhar no pacto nacional pela alfabetização na idade certa. Revista SODEBRAS, v. 10, p. 15-19, 2015.

PINHO, M. J.; MORAES, M. J. S. Contexto Histórico da Escola do Canela: uma concepção criativa na formação continuada docente. Revista FAED - UNEMAT, v. 1, p. 35-56, 2015.

PINHO, M.J.; MORAES, M.J.S. Contexto Histórico da Escola do Canela: uma concepção criativa na formação continuada docente. Revista FAED - UNEMAT, v. 1, p. 35-56, 2015.

ARAUJO, M. A. A.; MENDES, M. E.; PINHO, M.J.; ALBUQUERQUE, Francisco Edvirges. Planejamento e prática interdisciplinar: Novos rumos para a docência no curso de Letras da UNIRG. Intersecções (Jundiaí), v. 2, p. 153-169, 2014.

PINHO, M.J.; NASCIMENTO, Elzimar Pereira. Formação de Professores: Côncavo e Convexo. Revista de Ciências Humanas, v. 15, p. 20-32, 2014.

PINHO, M.J.; PINHO, E. M.C.O conhecimento pertinente e inovador: Um desafio para educação e para escola na sociedade contemporânea. Revista Electrónica de Investigación y Docencia, v. 1, p. 1-17, 2014.

DUARTE, J.G.; AMILSON, J.; PINHO, M.J.O discurso da inovação no referencial curricular de língua portuguesa para o ensino fundamental - $1^{\circ}$ ao $9^{\circ}$ ano: uma análise semiótica. Revista Querubim, v. 1, p. 95-102, 2014. 
DUARTE, J.G.; PINHO, M.J. Análise discursiva: O ensino de língua estrangeira em uma sala de aula. Revista Querubim, v. 2, p. 45-51, 2014.

PINHO, M.J.; SOUZA, K.P.Q. Escola contemporânea criativa e inovadora na transição de paradigmas. Eventos Pedagógicos, v. 5, p. 89-104, 2014.

PINHO, M. J.; SOUZA, K. P. Q. Ciência e produção do conhecimento contemporâneo na perspectiva da criatividade. Desafios: Revista Interdisciplinar da Universidade Federal do Tocantins, v. 1, p. 146-160, 2014.

PINHO, E.M.C.; PINHO, M.J. A educação e a pedagogia na transição da modernidade para contemporaneidade: da escola cartesiana à escola criativa. Revista Querubim, v. 1, p. 31-36, 2013.

PINHO, M.J.; FERREIRA, Tânia do Socorro. A formação de professores sob os vários olhares: Tradicional e da complexidade. Revista Querubim, v. 2, p. 128136, 2013.

GRANADA, R.; SANTOS, J.S.; MEDEIROS, V. S.; PINHO, M. J. A universidade e os desafios da formação docente em uma era de supercomplexidade. Entretextos (UEL), v. 13, p. 87-107, 2013.

ALMEIDA, Severina Alves; ALBUQUERQUE, Francisco Edvirges; PINHO, M.J. Transdisciplinaridade e educação intercultural: a formação do professor indígena Apinayé em perspectiva. Revista Ibero-Americana de Estudos em Educação, v. 8, p. 825-846, 2013.

ATAIDE, Denyse Mota da Silva; PINHO, M.J. Letramento digital e alfabetização tecnológica: reflexões a partir de um estudo com alunos do PARFOR. Educacao, Formacao \& Tecnologias, v. 6, p. 68-79, 2013.

ATAIDE, Denyse Mota da Silva; PINHO, M. J. Letramanto Digital e Formação de Professor: Faces e interfaces. Cadernos de Pesquisa: Pensamento Educacional (Curitiba. Impresso), v. 7, p. 45-67, 2012.

ATAIDE, Denyse Mota da Silva; PINHO, M. J.; MAGALHÃES, Hilda Gomes Dutra. Educação a distância e formação de professores: Desafios e perspectivas no contexto do paradigma educacional emergente. Revista Querubim, v. 1, p. 46-57, 2012.

\section{LIVROS PUBLICADOS/ORGANIZADOS OU EDIÇÕES}

PINHO, M. J.; SUANNO, Marilza Vanessa Rosa (Org.); SUANNO, J. H. (Org.). Projetos Criativos na Prática Pedagógica: Cantar e Encantar a Aprendizagem. 1. ed. Goiânia: Editora Espaço Acadêmico, 2015. v. 1. 245p.

PINHO, M. J.; SUANNO, Marilza Vanessa Rosa (Org.); SUANNO, J. H. (Org.); NASCIMENTO, Elzimar Pereira (Org.). Complexidade, interdisciplinaridade e transdisciplinaridade na educação superior. 1. ed. Goiânia: Editora Espaço Acadêmico, 2015. v. 1. 1p.

PINHO, M. J.; SUANNO, Marilza Vanessa Rosa (Org.); SUANNO, J. H. (Org.). 
Formação de Professores e Interdisciplinaridade: diálogo investigativo em construção. 1. ed. Goiânia: América, 2014. v. 1. 1p.

\section{CAPÍTULOS DE LIVRO}

SUANNO, Marilza Vanessa Rosa; SUANNO, J. H.; PINHO, M. J. Escola, Criatividade e Projetos Ecoformadores. In: Carlos Cardoso Silva; Sandra Valéria Limonte Rosa. (Org.). Anos Iniciais do Ensino Fundamental: Política, gestão, formação de professores e ensino. 1ed.Campinas/SP: Mercado de Letras, 2015, v. 1, p. 175-195.

PINHO, M. J.; SOUZA, K. P. Q.; MORAES, M. J. S.; OLIVEIRA, L. B.; LIMA, M. L. A. O universo da escola municipal de tempo integral Daniel Batista - contextualização. In: Maria José de Pinho; Marilza Vanessa Rosa Suanno; João Henrique Suanno. (Org.). Projetos Criativos na Prática Pedagógica: Cantar e Encantar a Aprendizagem. 1ed. Goiânia: Editora Espaço Acadêmico, 2015, v. 1, p. 17-36.

PINHO, M. J.; MORAES, M. J. S.; SOUZA, K. P. Q.; LIMA, M. A.; REZENDE, S. F. C. Ações criativas na escola de tempo integral Daniel Batista. In: Maria José de Pinho; Marilza Vanessa Rosa Suanno; João Henrique Suanno. (Org.). Projetos Criativos na Prática Pedagógica: Cantar e Encantar a Aprendizagem. 1ed.Goiânia: Editora Espaço Acadêmico, 2015, v. 1, p. 37-54.

PINHO, E. M. C.; NASCIMENTO, Elzimar Pereira; PINHO, M. J.; BRINGMANN, L. $\mathrm{O}$. A escola de mãos dadas com as diferenças: uma experiência de criatividade e colaboração no sul do Tocantins. In: Maria José de Pinho; Marilza Vanessa Rosa Suanno; João Henrique Suanno. (Org.). Projetos Criativos na Prática Pedagógica: Cantar e Encantar a Aprendizagem. 1ed.Goiânia: Editora Espaço Acadêmico, 2015, v. 1, p. 55-76.

PINHO, M. J.; MORAES, M. J. S. Políticas Públicas Educacionais para o Ensino Fundamental: propostas criativas do plano nacional de educação (2014-2024). In: LAGARES, Rosilene; ROCHA, Damião; OLIVEIRA, João Ferreira. (Org.). Educação no Território Municipal. 1ed.Goiânia: Espaço Acadêmico, 2015, v. 1, p. 253-278.

PINHO, M. J.; NASCIMENTO, Elzimar Pereira. Formação do formador: Repensar a caminhada da qualidade educacional da universidade. In: Rosemeire Parada Granada M. da Costa; Maria Elaine Mendes; Marcilene de Assis Alves Araújo. (Org.). Diálogos entre letras: Propostas em ensino, linguística e formação de professores. 1ed.Campinas: Pontes, 2015, v. 1, p. 71-88.

ALMEIDA, Severina Alves; ALBUQUERQUE, Francisco Edvirges; PINHO, M. J. OS APINAYÉ E A EDUCAÇÃO ESCOLAR: um estudo sociolinguístico das aldeias São José e Mariazinha. In: Luiza Helena Oliveira da Silva; Márcio Araújo de Melo; Luiz Roberto Peel Furtado de Oliveira. (Org.). Ensino de Língua e Literatura: pesquisas na pós-graduação. 1ed.Palmas: EDUFUT, 2014, v. 1, p. 1-232. 
ALMEIDA, N. R.; MELO, M. A.; PINHO, M. J. Avaliação prova Brasil: Paradigma tradicional ou emergente. In: Maria José de Pinho; Marilza Vanessa Rosa Suanno; João Henrique Suanno. (Org.). Formação de professores e Inter/ transdisciplinaridade: Diálogo investigativo em construção. 1ed.Goiânia: América Ltda., 2014, v. 1, p. 9-449.

AMILSON, J.; PINHO, M. J. Inovando a aula: Considerações sobre a relação professoraluno. In: Maria José de Pinho; Marilza Vanessa Rosa Suanno; João Henrique Suanno. (Org.). Formação de professores e Inter/transdisciplinaridade: Diálogo investigativo em construção. 1ed.Goiânia: América Ltda, 2014, v. 1, p. 9-449.

SILVA, O. P.; SANTOS, J. S.; PINHO, M. J. Ensino de Língua Materna na perspectiva do paradigma emergente. In: Maria José de Pinho; Marilza Vanessa Rosa Suanno; João Henrique Suanno. (Org.). Formação de professores e Inter/transdisciplinaridade: Diálogo investigativo em construção. 1ed.Goiânia: América Ltda., 2014, v. 1, p. $1-445$.

DUARTE, J. G.; PINHO, M. J. A criatividade e a interdisciplinaridade no referencial curricular de língua estrangeira. In: Maria José de Pinho; Marilza Vanessa Rosa Suanno; João Henrique Suanno. (Org.). Formação de professores Inter/ transdisciplinaridade: Dialogo investigativo em construção. 0ed.Goiânia: América, 2014, v. 1, p. 1-458.

PINHO, M. J.; MAGALHÃES, Hilda Gomes Dutra. Interdisciplinaridade e formação docente no mestrado em ensino de língua e literatura da UFT: Teoria e prática. In: Akiko Santos; João Henrique Suanno; Marilza Vanessa Suanno. (Org.). Didática e Formação de Professores: Complexidade e Transdisciplinaridade. 1ed.Porto Alegre: Sulina, 2013, v. 1, p. 299-318.

PINHO, M. J.; SUANNO, Marilza Vanessa Rosa. Desafios da Educação Superior: Valorização do ensino de graduação e pedagogia universitária. In: SANTANA, Jocyléia; ROCHA, Damião; APOLINÁRIO, Juciene; ROLIM, Carmem. (Org.). Resiliências Educativas. 1ed.Goiânia: América, 2013, v. 1, p. 9-276.

SOUZA, K. P. Q.; PINHO, M. J. Formação e profissionalização docente na mudança de paradigma. In: BEVILAQUA, Aluisio Pampolha; SOUSA, Antônio Cícero; RECH, Hildemar Luiz; TROMPIERI, Nicolino; SANTOS, Theotonio. (Org.). Seminário Paradigma da economia global e desenvolvimento sustentável à formação discente e docente. 1ed.Fortaleza: UFC; INVERTA, 2013, v. 1, p. 317-.

\section{TRABALHOS COMPLETOS PUBLICADOS EM ANAIS DE CONGRESSOS}

BARROS, T. C.; PINHO, M. J. Práticas pedagógicas com indícios de criatividade no âmbito do Pacto Nacional pela Alfabetização na Idade Certa. In: VI Encontro Interregional norte, nordeste e centro-oeste sobre formação docente para educação Superior e Básica - ENFORSUP / I Encontro Internacional sobre a formação 
docente para Educação Básica e Superior - INTERFOR, 2015, BRASÍLIA. VI ENFORSUP / I INTERFOR. BRASÍLIA, 2015. v. 1.

SOUZA, K. P. Q.; PINHO, M. J. Formação e Inovação na Educação Básica: uma perspectiva criativa na contemporaneidade. In: VI Encontro Inter-regional norte, nordeste e centro-oeste sobre formação docente para educação Superior e Básica - ENFORSUP / I Encontro Internacional sobre a formação docente para Educação Básica e Superior INTERFOR, 2015, BRASÍLIA. VI ENFORSUP - I INTERFOR. BRASÍLIA, 2015. v. 1.

PINHO, M. J.; MORAIS, M. J. S.; SOUZA, K. P. Q. Escola Municipal de Tempo Integral Daniel Batista: Perspectivas criativas e inovadoras. In: Seminário da Rede Internacional de Escolas Criativas, 2014, Goiânia. Escola Municipal de Tempo Integral Daniel Batista: Perspectivas criativas e inovadoras, 2014. v. 1. p. 333-340.

MORAIS, M. J. S.; PINHO, M. J. Perspectivas criativas e inovadoras no processo de formação continuada. In: II congresso Nacional de Formação de Professores, 2014, Águas de Lindóias. Por uma Revolução no Campo da Formação de Professores, 2014. v. 1. p. 1-13.

PINHO, E. M. C.; PINHO, M. J. Relações da Memória: a prática pedagógica e as necessidades formativas dos professores do ensino técnico profissionalizante no IFTO-Campus Gurupi. In: II congresso Nacional de Formação de Professores, 2014, Águas de Lindóias. Por uma Revolução no Campo da Formação de Professores, 2014. v. 1.

DUARTE, J. G.; PINHO, M. J. A Criatividade e a Motivação no Processo de EnsinoAprendizagem de Língua Inglesa. In: ABRALIN em Cena: Pesquisas Linguísticas e Demandas do Ensino Básico, 2014, Araguaína. Pesquisas Linguísticas e Demandas do Ensino Básico. Araguaína, 2014. v. 1. p. 594-608.

AMILSON, J.; PINHO, M. J. Planejamento e Acaso: Uma Análise do Discurso de Professoras de Língua Portuguesa sobre Criatividade. In: ABRALIN em Cena: Pesquisas Linguísticas e Demandas do Ensino Básico, 2014, Araguaína. Pesquisas Linguísticas e Demandas do Ensino Básico. Araguaína, 2014. v. 1. p. 396-413.

ATAIDE, Denyse Mota da Silva; PINHO, M. J. Gêneros Textuais e Ensino da Língua Portuguesa: Desenvolvendo Práticas Criativas na Sala de Aula. In: ABRALIN em Cena: Pesquisas Linguísticas e Demandas do Ensino Básico, 2014, Araguaína. Pesquisas Linguísticas e Demandas do Ensino Básico. Araguaína, 2014. v. 1. p. 203-218.

PINHO, M. J.; SOUZA, K. P. Q.; MORAES, M. J. S. Práticas criativas na Escola Municipal de Tempo Integral Daniel Batista. In: VI Fórum Internacional de Innovación y Creatividad: Escuelas y Aulas Creativas, 2014, Barcelona. ESCUELAS Y AULAS CREATIVAS Reflexiones y Experiencias. Barcelona - Espanha: Universitat de Barcelona, 2014. p. 188-195.

PINHO, M. J.; ARAUJO, E. R. Os recursos audiovisuais no espaço escolar. In: Fórum 
Internacional Inovação e Criatividade, 2013, Palmas. Inovação e Criatividade, 2013. v. 1. p. 1.

PINHO, M. J.; WIENNERY, C. Análise de práticas letradas em aula do ensino médio: Enfoque de práticas sociais em textos de língua portuguesa. In: Fórum Internacional Inovação e Criatividade, 2013, Palmas. Inovação e Criatividade, 2013. v. 1. p. 1.

PINHO, M.J.; FERREIRA, Tânia do Socorro. A interferência da formação continuada nas práticas de leitura dos professores. In: Fórum Internacional Inovação e Criatividade, 2013, Palmas. Inovação e Criatividade, 2013. v. 1. p. 1.

PINHO, M.J.; AMILSON, J. Ser pedra ou vidraça: Um estudo sobre criatividade e inovação no ensino de português. In: Fórum Internacional Inovação e Criatividade, 2013, Palmas. Inovação e Criatividade, 2013. v. 1. p. 1.

PINHO, E.; PINHO, M.J. A prática educativa inovadora e reorganização do saber: Um novo olhar para escola. In: Fórum Internacional Inovação e Criatividade, 2013, Palmas. Inovação e Criatividade, 2013. p. 1.

DUARTE, J.G.; PINHO, M.J. Escola criativa: A criatividade e a inovação no ensinoaprendizagem de língua inglesa. In: Fórum Internacional Inovação e Criatividade, 2013, Palmas. Inovação e Criatividade, 2013. v. 1. p. 1.

DUARTE, J.G.; MILANI, S. E.; PINHO, M.J. As contribuições dos ensinamentos de Leonard Bloomfield para a linguística. In: Círculo Fluminense de Estudos Filológicos e Linguísticos, 2013, Rio de Janeiro. Cadernos do CNLF. Rio de Janeiro, 2013. v. XVII. p. 28-41.

DUARTE, J.G.; PINHO, M.J.; ARAUJO, M. A. A. O processo de ensino-aprendizagem em uma sala de aula de língua inglesa no ensino fundamental em palmas - TO. In: III Simpósio Nacional De Letras E Linguística In Simpósio Internacional De Letras E Linguística, 2013, Catalão. Linguagem, Cultura, Identidade e Ensino, 2013. v. 3. p. $594-604$

DUARTE, J.G.; NEGRI, C. S.; PINHO, M.J. Análise do discurso: o discurso em uma sala de aula de língua inglesa. In: I Seminário de Língua e Literatura da UEPA, 2013, Conceição do Araguaia. Anais do Seminário de Língua e Literatura da UEPA, 2013. v. 1. p. 1-10.

PINHO, M.J.; WIENNERY, C. Letramento e educação matemática: Análise práticas sociais no âmbito das aulas do ensino fundamental. In: Fórum Internacional Inovação e Criatividade, 2013, Palmas. Inovação e Criatividade, 2013. v. 1. p. 1.

FERREIRA, Tânia do Socorro; PINHO, M.J.; RODRIGUES, Wagner Silva. A interferência da formação continuada nas práticas de leitura dos professores. In: XXIV Jornada nacional do grupo de estudos linguísticos do Nordeste, 2012, Natal. Anais da Jornada do Grupo de Estudos Linguísticos do Nordeste. Natal: EDUFRN, 2012.

PINHO, M.J.; PASSOS, Vânia M. de Araújo. Interação virtual e o estágio supervisionado o curso de Biologia da UFT. In: II fórum internacional sobre prática docente 
universitária, planejamento e avaliação no contexto global, 2012, Uberlândia. Anais do fórum internacional sobre prática docente universitária. Uberlândia, 2012. v. 1. p. 186-196.

PINHO, M.J.; PASSOS, Vânia M. de Araújo. Interação virtual e o estágio supervisionado o curso de Biologia da UFT. In: II fórum internacional sobre prática docente universitária, 2012, Uberlândia. ANAIS DO FÓRUM INTERNACIONAL SOBRE PRÁTICA DOCENTE UNIVERSITÁRIA Uberlândia, 2012. v. 1. p. 186-196.

\section{RESUMOS EXPANDIDOS PUBLICADOS EM ANAIS DE CONGRESSOS}

FARIA, E.M.S.; PINHO, M.J. O ensino da língua portuguesa e os gêneros textuais: Das concepções epistemológicas às práticas criativas na sala de aula. In: XVIII Congresso Nacional de Linguística e Filologia, 2014, Rio de Janeiro. Ensino de Língua e Literatura, 2014. v. XVIII. p. 10-15.

SOUZA,K.P.Q; PINHO, M.J. Formação e profissionalização docente na mudança de paradigma. In: O paradigma da economia global e desenvolvimento sustentável à formação docente e discente em educação, 2013, Fortaleza. A crise da economia global e de paradigmas nas ciências da educação e formação de educadores. Fortaleza: REGGEN-UFC, 2013. v. 1. p. 1.

MORAES, M.J.S.; PINHO, M.J. Formação de professores: Uma ruptura paradigmática. In: O paradigma da economia global e desenvolvimento sustentável 'formação docente e discente em educação, 2013, Fortaleza. A crise da economia global e de paradigmas nas ciências da educação e formação de educadores. Fortaleza: REGGEN-UFC, 2013. v. 1. p. 1.

\section{OUTRAS PRODUÇÕES BIBLIOGRÁFICAS}

PINHO, M.J.; SUANNO, Marilza Vanessa Rosa; SUANNO, J.H. Projetos Criativos na Prática Pedagógica: Cantar e Encantar a Aprendizagem. Goiânia, 2015. (Prefácio, Posfácio/Apresentação).

PINHO, M.J.; SUANNO, Marilza Vanessa Rosa; SUANNO, J.H.; NASCIMENTO, Elzimar Pereira. Complexidade, interdisciplinaridade e transdisciplinaridade na educação superior. Goiânia, 2015. (Prefácio, Posfácio/Apresentação).

PINHO, M.J.; SUANNO, Marilza Vanessa Rosa; SUANNO, J.H. Formação de professores e interdisciplinaridade: Diálogo investigativo em construção. Goiânia, 2014. (Prefácio, Posfácio/Apresentação).

PINHO, M. J.; QUEIROZ, H.; CILLI, M. A. L. PIBIC 2013- Melhores trabalhos da iniciação científica da UFT. Palmas, 2014. (Prefácio, Posfácio/Apresentação).

LEITE, S.F.; JEFFREY, D.C.; FONTANA, S.; VOLPE, G.C. M.; PINHEIRO, N.S.; FARIA, E. M. S.; SOLIGO, A.F.; ROSA, A.S.; DOMBOSCO, C.; PINHO, M.J. A Educação de Jovens e Adultos: Questões atuais. Curitiba/PR, 2013. (Prefácio, Posfácio/Prefácio). 
A equipe da Universidade Regional de Blumenau - FURB, coordenada pela Profa. Dra. Vera Lúcia de Souza e Silva é composta por 7 mestrandos, 5 graduandos e 2 alunos iniciação cientifica. Esta equipe já publicou 5 artigos completos publicados em periódicos; 4 livros publicados/ organizados ou edições; 15 capítulos de livros publicados; 5 trabalhos completos publicados em anais de congressos e 8 resumos publicados em anais de congressos. As pesquisas da equipe estão vinculadas à formação de professores, ensino de ciências e biologia e escolas criativas.

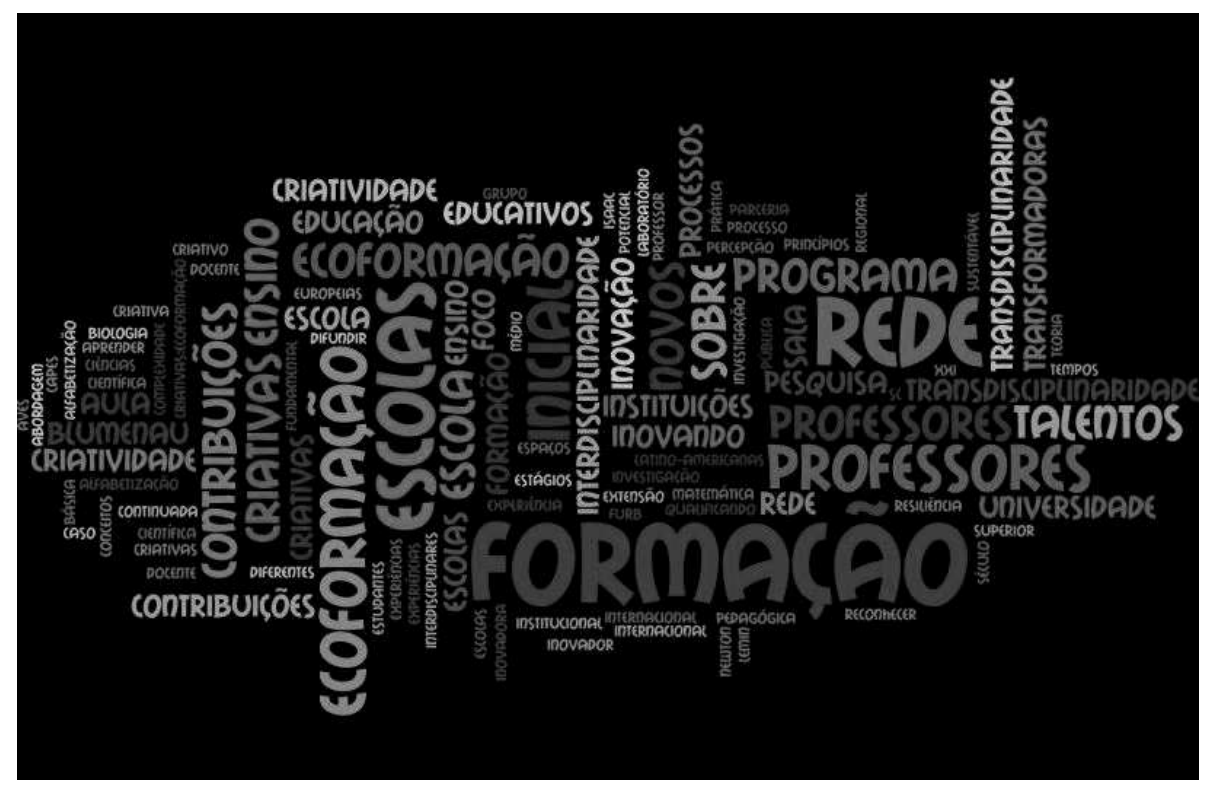

\section{ARTIGOS COMPLETOS PUBLICADOS EM PERIÓDICOS}

SILVA, V. L.S.; SOUZA, R. Rede internacional de escolas criativas: contribuições na formação de professores. Revista Electrónica de Investigación y Docencia, v. 13, p. 117-134, 2015.

CARDOSO, D.; SILVA, V.L.S. Investigação sobre criatividade em uma escola da rede pública de Blumenau - SC. Revista Electrónica de Investigación y Docencia, v. 11, p. 107-122, 2014.

SILVA, V.L.S.; Contribuições dos princípios da complexidade no processo de aprender biologia na formação inicial de professores. Enseñanza de las Ciencias, v. 01, p. 3287-3291, 2013.

SILVA, V.L.S.; FACHINI, F; PFIFFER, C. S. Interdisciplinaridade no ensino de 
Ciências: uma experiência pedagógica inovadora. Enseñanza de las Ciencias, v. 01, p. 3297-3301, 2013.

SILVA, V.L.S.; A Transdisciplinaridade na formação inicial de Professores. Dynamis (FURB. Online), v. 19, p. 19-32, 2013.

\section{LIVROS PUBLICADOS/ORGANIZADOS OU EDIÇÕES}

SCHROEDER, E.; SILVA, V.L.S. Novos Talentos: processos educativos em ecoformação. 01. ed. Blumenau: Nova Letra, 2014. v. 01.

SCHROEDER, E.; SILVA, V.L.S. Estágios em foco: pesquisa, teoria e prática na formação do professor na Universidade Regional de Blumenau. 1. ed. Blumenau: EDIFURB, 2014. v. 01. 205p

TORRE, S.L.; PUJOL, M.A.; SILVA, V.L.S. Inovando na sala de aula: instituições transformadoras. 01. ed. Blumenau: Nova Letra, 2013. v. 01. 215p.

CERVI, G.M.; STOPASSOLI, M.A.; HEINIG, O.L.O. M.; FONTES, P. N.; SILVA, V.L.S. Formação Docente: qualificando conceitos em diferentes tempos e espaços. 1. ed. Blumenau: EDIFURB, 2013. v. 1. 141p.

\section{CAPÍTULOS DE LIVROS PUBLICADOS}

PFIFFER, C.S.; FACHINI, F.; DALLABONA, K.G.; SILVA, V.L.S. Contribuições da Interdisciplinaridade para a Alfabetização Científica no Ensino Médio. In: Ricardo Kazama et al. (Org.). Interdisciplinaridade: teoria e prática. 1ed.Florianópolis: UFSC/EGC, 2014, v. 02, p. 265-288.

SILVA, V.L.S.; TIRONI, C.R. Experiências Interdisciplinares na Educação Básica: o caso do Laboratório de Educação Matemática Isaac Newton - LEMIN. In: Ricardo Kazama ... [et al.]. (Org.). Interdisciplinaridade: teoria e prática. 1ed.Florianópolis: UFSC/EGC, 2014, v. 2, p. 289-312.

SCHROEDER, E.; SILVA, V.L.S. O ciclo de ecoformação e biodiversidade na FURB como uma experiência de formação de professores da educação básica. In: Edson Schroeder; Vera Lúcia de Souza e Silva. (Org.). Novos Talentos: processos educativos em ecoformação. 01ed.Blumenau: Nova Letra, 2014, v. 01, p. 15-18.

TORRE, S.L.; SILVA, V.L.S. Ecoformação e transdisciplinaridade na rede de escolas criativas. In: Schroeder, E.; SILVA, V.L.S. (Org.). Novos Talentos: processos educativos em ecoformação. 01ed.Blumenau: Nova Letra, 2014, v. 01, p. 29-44.

SCHROEDER, E.; SILVA, V.L.S. O estágio na formação inicial de professores na abordagem da ecoformação e transdisciplinaridade. In: Edson Schroeder; 
Vera Lúcia de Souza e Silva. (Org.). Novos Talentos: processos educativos em ecoformação. 01ed.Blumenau: Nova Letra, 2014, v. 01, p. 45-54.

FACHINI, F.; SILVA, V.L.S. Ecoformação de Professores no Programa Novos Talentos da CAPES. In: Edson Schroeder; Vera Lúcia de Souza e Silva. (Org.). Novos Talentos: processos educativos em ecoformação. 01ed.Blumenau: Nova Letra, 2014, v. 01, p. 89-112.

.PIONTKEWICZ, S.C. ; SILVA, V.L.S. . Ações ecoformadoras numa comunidade rural no município de São Bento do Sul/SC. In: Edson Schroeder; Vera Lúcia de Souza e Silva. (Org.). Novos Talentos: processos educativos em ecoformação. 01ed. Blumenau: Nova Letra, 2014, v. 01, p. 193-204.

PUKALL, J.; ANDRADE, R.; SILVA, V. L. S. Escola Sustentável e Rede de Escolas Criativa parceria entre Escola e Universidade. In: Edson Schroeder; Vera Lúcia de Souza e Silva. (Org.). Novos Talentos: processos educativos em ecoformação. 01ed. Blumenau: Nova Letra, 2014, v. 01, p. 231-244.

SILVA, V.L.S; A coordenação dos estágios nas licenciaturas da FURB. In: Edson Schroeder; Vera Lucia de Souza e Silva. (Org.). Estágios em foco: pesquisa, teoria e prática na formação do professor na Universidade Regional de Blumenau. 1ed. Blumenau: EDIFURB, 2014, v. 1, p. 195-205.

TOMIO, D.; SCHROEDER, E.; SILVA, V.L.S. O professor de ciências da educação básica e a sua formação na licenciatura como pesquisador. In: SCHROEDER, E.; SILVA, V.L.S. (Org.). Estágios em foco: pesquisa, teoria e prática na formação do professor na Universidade Regional de Blumenau. 1ed.Blumenau: EDIFURB, 2014, v. 1, p. 148-167.

SILVA, V.L.S.; Estágio na formação de professores no ensino superior: uma vivência transdisciplinar. In: Saturnino de la Torre; Maria Antônia Pujol; Vera L. S. Silva. (Org.). Inovando na sala de aula: instituições transformadoras. 01ed.Blumenau: Nova Letra, 2013, v. 01, p. 132-148.

SILVA, V.L.S.; Contribuições do Programa Institucional Rede de Escolas Criativas da FURB para a formação docente. In: Marilza V.R. Suanno; Maria Gloria Dittrich; Maria Antónia Pujol Maura. (Org.). Resiliência, Criatividade e Inovação. 01ed. Goiânia: UEG, 2013, v. 01, p. 234-244.

SILVA, V.L.S.; Ecoformação e Rede Internacional de Escolas Criativas. In: SEVEGNANI, L.; SCHROEDER, E. (Org.). Biodiversidade Catarinense: características, potencialidades ameaças. 01ed.Blumenau: EDIFURB, 2013, v., p. 28-29.

MENEZES, C.; SCHROEDER, E.; SILVA, V.L.S.; LONGUI, A.; BUCH, G. Ações concretas para o Desenvolvimento de Clubes de Ciências como espaço de 
alfabetização científica e ecoformação na educação básica. In: Marlene Zwierewicz. (Org.). Criatividade e Inovação no Ensino Superior: experiências latino-americanas e europeias em foco. 1ed. Blumenau: Nova Letra, 2013, v. 1, p. 309-328.

CERVI, G.; SILVA, V.L.S. Coordenando o PIBID da FURB: intervenções e contribuições. In: Gicele M. Cervi; Marica A. Stopassoli; Otilia Lizete de oliveira MArtins Heinig; Patrícia Neto Fontes; Vera Lúcia de Souza e Silva. (Org.). Formação Docente: qualificando conceitos em diferentes tempos e espaços. 1ed.Blumenau: EDIFURB, 2013, v. 1, p. 21-34.

\section{TRABALHOS COMPLETOS PUBLICADOS EM ANAIS DE CONGRESSOS}

TIRONI, C.R.; SILVA, V.L.S. Experiências Interdisciplinares na Educação Básica: o caso do Laboratório de Educação Matemática Isaac Newton. In: Simpósio Internacional sobre Interdisciplinaridade no Ensino, na Pesquisa e na Extensão-Região Sul, 2013, Florianópolis. Simpósio Internacional sobre Interdisciplinaridade no Ensino, na Pesquisa e na Extensão Região Sul-Anais. Florianópolis: CAPES, 2013. v. 01. p. 11-26.

FACHINI, F.; ISOLANI, L.G.; SILVA, V.L.S. A Transdisciplinaridade na formação inicial de Professores. In: Simpósio Internacional sobre Interdisciplinaridade no Ensino, na Pesquisa e na Extensão-Região Sul, 2013, Florianópolis. Simpósio Internacional sobre Interdisciplinaridade no Ensino, na Pesquisa e na Extensão Região Sul-Anais. Florianópolis: CAPES, 2013. v. 01. p. 40-55.

FACHINI, F.; SILVA, V.L.S. Rede de Escolas Criativas: contribuições na formação continuada de professores. In: Simpósio Internacional sobre Interdisciplinaridade no Ensino, na Pesquisa e na Extensão-Região Sul, 2013, Florianópolis. Simpósio Internacional sobre Interdisciplinaridade no Ensino, na Pesquisa e na Extensão Região Sul-Anais. Florianópolis: CAPES, 2013. v. 01. p. 56-70.

ANDRADE, M.F.M.; OLIVEIRA, P.L.S.; TOMIO, D.; SILVA, V.L.S. Além do quarto do Hospital: aprendendo ciências em uma classe hospitalar. In: 65a. Reunião Anual da SBPC, 2013, Recife. Anais da 65a. reunião da SBPC, 2013.

TIRONI, C.R.; ISOLANI, L.G.; SILVA, V.L.S. Laboratório de Educação Matemática ISaac Newton: um estudo de caso na perspectiva da etnomatemática. In: Congresso Internacional de Ensino da Matemática, 2013, Canoas. Anais do CIEM, 2013.

\section{RESUMOS PUBLICADOS EM ANAIS DE CONGRESSOS}

SILVA, V.L.S.; GUZTZASKI, A. C. Percepção sobre aves de um grupo de estudantes 
de uma escola de ensino fundamental: uma investigação sobre a alfabetização científica e a ecoformação. In: X Seminário Integrado das Licenciaturas, Seminário em Educação e III Encontro PARFOR FURB, 2014, Blumenau. X Seminário Integrado das Licenciaturas, Seminário em Educação e III Encontro PARFOR FURB, 2014.

SILVA, V.L.S.; VEBER, B.; GONCALVES, G.H.P. Formação inicial de professores na abordagem da ecoformação e transdisciplinaridade. In: X Seminário Integrado das Licenciaturas, Seminário em Educação e III Encontro PARFOR FURB, 2014, Blumenau. X Seminário Integrado das Licenciaturas, Seminário em Educação e III Encontro PARFOR FURB, 2014

TIRONI, C. R.; SILVA, V.L.S. Etnomatemática na Formação Continuada de Professores: estudo de caso do LEMIN. In: 7a. MIPE, 2013, Blumenau. Anais da 7a. MIPE, 2013.

CARDOSO, D.; SILVA, V.L.S. Investigação sobre criatividade em uma escola da rede pública de Blumenau SC. In: 7a. MIPE, 2013, Blumenau. Anais da 7a. MIPE, 2013.

FACHINI, F.; SILVA, V.L.S.; IMHOF, A.M.Q.; ISOLANI, L.G. Programa Rede de Escolas Criativas: ecoformação e criatividade no ensino, pesquisa e extensão. In: 7a. MIPE, 2013, Blumenau. Anais da 7a. MIPE, 2013.

ALBERTO, S.; SILVA, V.L.S.; SIMAO, V.L. ESCOLAS CRIATIVAS: reconhecer e difundir o potencial inovador e criativo da escola do século XXI. In: 7a. MIPE, 2013, Blumenau. Anais da 7a. MIPE, 2013.

SIMAO, V.L.; SILVA, V.L.S.; FACHINI, F. Formação continuada para a criatividade: uma experiência de extensão. In: 7a. MIPE, 2013, Blumenau. Anais da 7a. MIPE, 2013.

PEDRO, J.C.; TOMIO, D.; SILVA, V.L.S. Ensino de Ciências na Perspectiva da ecoformação: uma proposta de estágio na formação inicial de professores. In: 7a. MIPE, 2013, Blumenau. Anais da 7a. MIPE, 2013.

A equipe do Centro Universitário Barriga Verde - Unibave, coordenado pela Profa. Dra. Marlene Zwierewicz já publicou 3 livros publicados/organizados ou edições; 9 capítulos de livros publicados; 2 trabalhos publicados em anais de congressos; 2 resumos publicados em anais de congressos e 1 artigo aceito para publicações, as pesquisas estão centradas na criatividade, ecoformação e projetos educacionais criativos.

A equipe do Estado de Goiás, coordenada pelo Prof. Dr. João Henrique Suanno -ESEFFEGO/MIELT/UEG é composta por três alunos de iniciação cientifica, 3 mestrandos, 1 pós-doutoranda e 2 especializandos. Esta equipe já publicou 
2 artigos completos publicados em periódicos; 8 livros publicados/organizados ou edições; 11 capítulos de livros publicados; 9 trabalhos completos publicados em anais de congressos, 2 resumos publicados em anais de congressos e 1 tese de doutorado, tendo por eixo norteador das pesquisas: transdisciplinaridade, interdisciplinaridade, escolas criativas e sustentabilidade com ênfase na formação de professores e na Educação Física Escolar.

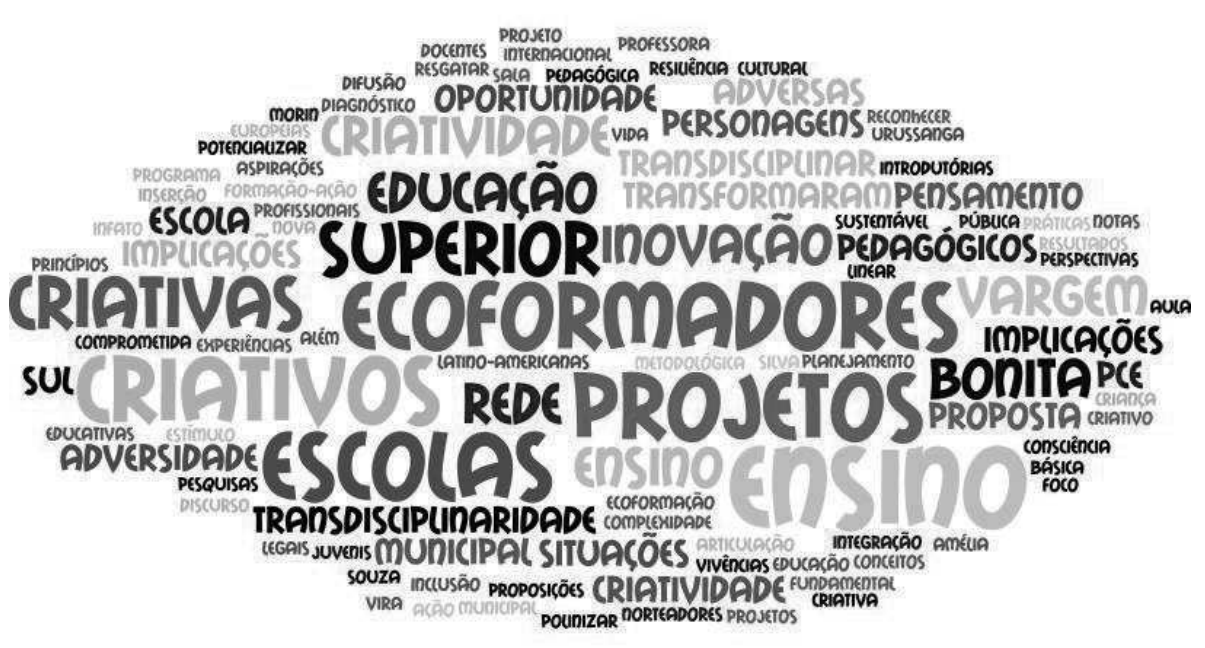

\section{LIVROS PUBLICADOS/ORGANIZADO OU EDIÇÕES}

Marlene; Lazaroto, Nadia de Lourdes Roseghini (Org.); Rozário, Verônica Spader (Org.); Mozzer, Cácia Raquel dos Santos (Org.). Resiliência, criatividade e inclusão no ensino: vivências de profissionais da educação de Vargem Bonita. 1. ed. Blumenau: Nova Letra, 2014. v. 1. 131p.

Marlene; Criatividade e inovação no Ensino Superior: experiências latino-americanas e europeias em foco. 1. ed. Blumenau: Nova Letra, 2013. v. 300. 341p.

TORRE, S.; Marlene. Criatividade na adversidade: personagens que transformaram situações adversas em oportunidade. 1. ed. Blumenau: Nova Letra, 2012. v. 300.189 p. 


\section{CAPÍTULOS DE LIVROS PUBLICADOS}

Marlene; MARIOTI, B. Implicações do Pensamento do Sul de Morin e dos Projetos Criativos Ecoformadores no 'Projeto Urussanga Vira Criança - Aspirações infato juvenis no planejamento municipal criativo e sustentável. In: Maria José de Pinho: Marilza Vanessa Rosa Suanno; João Henrique Suanno. (Org.). Projetos criativos na prática pedagógica: cantar e encantar a aprendizagem. 1ed.Goiânia: Editora Espaço Acadêmico, 2015, v. 1, p. 193-208.

Marlene; TORRE, Saturnino de la; SILVA, M.C.; SILVEIRA, L.; SILVA, R.M. Uma educação comprometida com a vida: implicações e resultados dos Projetos Criativos Ecoformadores na Escola Municipal de Ensino Fundamental Professora Amélia de Souza Silva. In: Maria José de Pinho: Marilza Vanessa Rosa Suanno; João Henrique Suanno. (Org.). Projetos criativos na prática pedagógica: cantar e encantar a aprendizagem. 1ed.Goiânia: Editora Espaço Acadêmico, 2015, v. 1, p. 209-230.

Lazaroto, Nadia de Lourdes Roseghini; Rozário, Verônica Spader; Mozzer, Cácia Raquel dos Santos; Marlene. A Rede Municipal de Vargem Bonita: articulação entre princípios legais e pedagógicos. In: Marlene Zwierewicz; Nadia de Lourdes Rosghini Lazaroto; Verônica Spader do Rozário; Cácia Raquel dos Santos Mozzer. (Org.). Resiliência, criatividade e inclusão no ensino: vivências de profissionais da educação de Vargem Bonita. 1ed.Blumenau: Nova Letra, 2014, v. 1, p. 15-26.

Marlene; Resgatar, reconhecer, potencializar e polinizar: perspectivas e proposições da Escola Criativa em Vargem Bonita. In: Marlene Zwierewicz; Nadia de Lourdes Roseghini Lazaroto, Verônica Spader do Rozário; Cácia Raquel dos Santos Mozer. (Org.). Resiliência, criatividade e inclusão no ensino: vivências de profissionais da educação de Vargem Bonita. 1ed.Blumenau: Nova Letra, 2014, v. 1, p. 39-58.

Marlene; Mozzer, Cácia Raquel dos Santos. Para além do discurso: criatividade e inovação em sala de aula. In: Marlene Zwierewicz; Nadia Lourdes Roseghini Lazaroto; Verônica Spader do Rozário; Cácia Raquel dos Santos Mozzer. (Org.). Resiliência, criatividade e inclusão no ensino: vivências de profissionais da educação de Vargem Bonita. 1ed.Blumenau: Nova Letra, 2014, v. 1, p. 111-132.

Marlene; Complexidade, transdisciplinaridade e ecoformação: conceitos norteadores das Escolas Criativas e suas implicações na difusão do Pensamento do Sul. In: Maria José de Pinho; Marilza Vanessa Rosa Suanno; João Henrique Suanno. (Org.). Formação de professores e interdisciplinaridade: diálogo investigativo em construção. 1ed.Goiânia: América, 2014, v. 1, p. 33-58.

Marlene; Do ensino linear ao ensino transdisciplinar: notas introdutórias para uma 
nova consciência na educação. In: Marlene Zwierewicz. (Org.). Criatividade e inovação no ensino superior: experiências latino-americanas e europeias em foco. 1ed.Blumenau: Nova Letra, 2013, v. 1, p. 19-34.

Marlene; Projetos Criativos Ecoformadores - PCE: inovação metodológica e estímulo à transdisciplinaridade no Ensino Superior. In: Marlene Zwierewicz. (Org.). Criatividade e inovação no Ensino Superior: experiências latino-americanas e europeias em foco. 1ed.Blumenau: Nova Letra, 2013, v. 1, p. 163-186.

Marlene; Da adversidade à resiliência: o princípio motivador da Escola Criativa. In: Saturnino de la Torre; Marlene Zwierewicz. (Org.). Criatividade na adversidade: personagens que transformaram situações adversas em oportunidade. 1ed.Blumenau: Nova Letra, 2012, v., p. 49-60.

\section{TRABALHOS COMPLETOS PUBLICADOS EM ANAIS DE CONGRESSOS}

Marlene; WILLEMANN, E.; ALBERTON, J. V.; VANDRESEN, S.; DUARTE, R. H.; DORREGAO, V.V.; BIANCO, M.; SOMARIVA, J.F.G. Implicações das Escolas Criativas e dos Projetos Criativos Ecoformadores no programa de formação-ação de docentes da Educação Básica e do Ensino Superior. In: VI SENPEX, 2015, Orleans. VI Seminário de Ensino, Pesquisa e Extensão: ciência e tecnologia para a promoção da educação e da vida. Orleans: Unibave, 2015. p. 591-597.

KRETSCHEK, I. H. R.; ZWIEREWICZ, M. Ação transdisciplinar em diagnóstico cultural: uma proposta para inserção dos Projetos Criativos Ecoformadores (PCE). In: V Seminário Internacional: Políticas Culturais, 2014, Rio de Janeiro. V Seminário Internacional: Políticas Culturais, 2014. p. 1-13.

\section{RESUMOS PUBLICADOS EM ANAIS DE CONGRESSOS}

Marlene; BIANCO, M.; GOMES, I. D. Transdisciplinaridade, pesquisa e internacionalização nas parcerias entre o Ensino Superior e o Sistema Municipal de ensino. In: V Congresso Integrado de Ensino, Pesquisa e extensão da Unidavi, 2015, Rio do Sul. Caderno de Resumo do V CIEPE. Rio do Sul: Unidavi, 2015. p. 266-266.

ZWIEREWICZ, Marlene ; BIANCO, M.; GUIZZO, I. A proposta pedagógica das Escolas Criativas na integração do Ensino Superior e a Rede Pública de Ensino. In: V Congresso Integrado de Ensino, Pesquisa e extensão da Unidavi, 2015, Rio do Sul. Caderno de Resumo do V CIEPE. Rio do Sul: Unidavi, 2015. p. 256-256. 
E.; LIMAVERDE, P. Escolas, práticas educativas e projetos pedagógicos: pesquisas da Rede Internacional de Escolas Criativas. Polyphonía, 2015.

A equipe do Estado de Goiás, coordenada pelo Prof. Dr. João Henrique Suanno -ESEFFEGO/MIELT/UEG é composta por três alunos de iniciação cientifica, 3 mestrandos, 1 pós-doutoranda e 2 especializandos. Esta equipe já publicou 2 artigos completos publicados em periódicos; 8 livros publicados/organizados ou edições; 11 capítulos de livros publicados; 9 trabalhos completos publicados em anais de congressos, 2 resumos publicados em anais de congressos e 1 tese de doutorado, tendo por eixo norteador das pesquisas: transdisciplinaridade, interdisciplinaridade, escolas criativas e sustentabilidade com ênfase na formação de professores e na Educação Física Escolar.

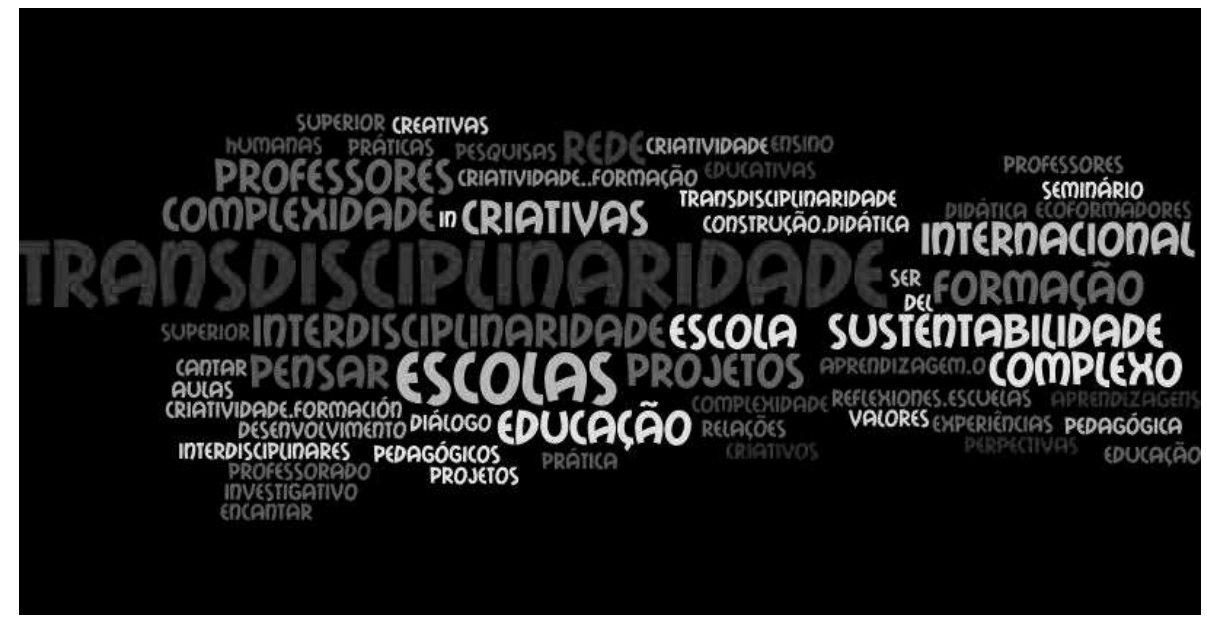

\section{ARTIGOS COMPLETOS PUBLICADOS EM PERIÓDICOS}

SUANNO, João Henrique; Estratégias Educativas Transdisciplinares Desenvolvidas No Colégio Logosófico De Goiânia. Revista Terceiro Incluído, v. 5, p. 145-162, 2015.

PAULA, M. V. G. Escola e cibercultura: breve reflexão acerca das TICs como recurso pedagógico. Polyphonia: Revista de Educação Básica do Cepae (UFG), v. 23, p. $231,2012$. 


\section{LIVROS PUBLICADOS/ORGANIZADOS OU EDIÇÕES}

SUANNO, João Henrique; SUANNO, Marilza Vanessa Rosa (Org.) ; PINHO, Maria José de (Org.) . Projetos Criativos na Prática Pedagógica: cantar e encantar a aprendizagem. 1. ed. Goiânia: Editora Espaço Acadêmico, 2015. v. Único. 232p.

SUANNO, João Henrique; SUANNO, Marilza Vanessa Rosa (Org.); PINHO, Maria José de (Org.); FERRAZ, Elzimar Pereira Nascimento (Org.). Complexidade, Interdisciplinaridade e Transdisciplinaridade na Educação Superior. 1. ed. Goiânia: Editora Espaço Acadêmico, 2015. v. Único. 188p.

SUANNO, João Henrique; MORAES, Maria Cândida (Org.). O pensar complexo na Educação: sustentabilidade, transdisciplinaridade e criatividade. $1^{\text {a }}$. ed. São Paulo: WAK Editora, 2014. v. Único. 232p.

SUANNO, João Henrique; SUANNO, Marilza Vanessa Rosa (Org.); PINHO, Maria José de (Org.). Formação de professores e interdisciplinaridade: diálogo investigativo em construção. 1. ed. Goiânia - Goiás: América, 2014. v. 1. 456p.

SUANNO, João Henrique; SUANNO, Marilza Vanessa Rosa (Org.); SANTOS, Akiko (Org.). Didática e Formação de Professores: Complexidade e Transdisciplinaridade. 1. ed. Porto Alegre - RS: Editora Sulina, 2013. v. 01. 344p.

JOSGRILBERT, Maria de Fátima Viegas; Experiências Interdisciplinares no Ensino Superior. 1. ed. Ponta Porã: EdFAMAG, 2015. v. 01. 190p.

JOSGRILBERT, Maria de Fátima Viegas; Experiências Interdisciplinares no Ensino Superior. 01. ed. Ponta Porã-MS: EdFAMAG, 2015. v. 01. 196p.

Viegas; Em busca do olhar da alma: uma abordagem interdisciplinar. $1^{\text {a. }}$ ed. Ponta Porã: Editora Magsul, 2012. v. 01.

\section{CAPÍTULOS DE LIVROS PUBLICADOS}

SUANNO, João Henrique ; SUANNO, Marilza Vanessa Rosa ; PINHO, Maria José . Escola, criatividade e projetos ecoformadores. In: Carlos Cardoso Silva e Sandra Valéria Limonta Rosa. (Org.). ANOS INICIAIS DO ENSINO FUNDAMENTAL: Política, Gestão, Formação de Professores e En. 1ed.Campinas - São Paulo: Mercado de Letras, 2015, v. 1, p. 175-190.

SUANNO, João Henrique; MORAES, Maria Cândida. Ecoformação, transdisciplinaridade e criatividade: a escola e a formação do cidadão do século XXI. In: João Henrique Suanno e Maria Cândida Moraes. (Org.). O pensar complexo na Educação: sustentabilidade, transdisciplinaridade e criatividade. 1ed.São Paulo: WAK Editora, 2014, v. 1, p. 171-182.

SUANNO, João Henrique ; SUANNO, Marilza Vanessa Rosa ; TOSCHI, Mirza Sea- 
bra; LIMONTA, Sandra Valéria . Pedagogía Logosófica e Estratégias Transdisciplinárias.. In: João Henrique Suanno; Marilza Vanessa Rosa Suanno; MIrza Seabra Toschi; Sandra Valéria Limonta. (Org.). Formación del professorado: perpectivas e reflexiones. NO PRELO. 1ed.Sevilla - Espanha: Círcolo Rojo, 2014, v. 1, p. 125-144.

SUANNO, João Henrique; Estrategias educativas transdisciplinarias desarrolladas en el Colegio Logosófico de Goiânia. In: Maria Antonia Pujol; Saturnino De la Torre; Nuria Lorenzo. (Org.). Escuelas y aulas Creativas Reflexiones y Experiencias. 1ed. Barcelona: ICE-UB, 2014, v. 1, p. 167-181.

SUANNO, João Henrique; SUANNO, Marilza Vanessa Rosa; CONTI, Carla; JUNQUEIRA, Lilian de Castro; PESSONI, Lucineide Maria de Lima; NICOLAU, Rita Acácia Correa; BORGES, Sueli Pereira; OLIVEIRA, Valdirene Alves de; ANDRADE, Viviane Arantes de; REIS, Marlene Barbosa de Freitas; SOBRAL, Osvaldo José. Análise Preliminar das publicações do CEPAE/UFG nos Anais do I Seminário RIEC (BRASIL). In: Maria Antonia Pujol; Saturnino De la Torre; Nuria Lorenzo. (Org.). ESCUELAS Y AULAS CREATIVAS Reflexiones y Experiencias. 1ed.Barcelona: ICE-UB, 2014, v. Único, p. 113-128.

SUANNO, João Henrique; Creatividad em la educación. Entrevistas a investigadores. In: PUJOL, María Antònia; RAJADELL, Núria; SUANNO, Marilza Vanessa Rosa. (Org.). Didáctica y Formación: una mirada transdisciplinar. 1ed.Sevilla - Espanha: Círculo Rojo Editora, 2013, v. Único, p. 285-301.

SUANNO, João Henrique; O desenvolvimento da criatividade em um ambiente transdisciplinar de aprendizagens. In: SUANNO, João Henrique; SUANNO, Marilza Vanessa Rosa; SANTOS, Akiko. (Org.). Didática e Formação de Professores: complexidade e transdisciplinaridade. 1ed.Porto Alegre - RS: Sulina, 2013, v. Único, p. 149-166.

Viegas; SUANNO, J. H. Uma experiência transdisciplinar no ensino superior. In: Pinho, Maria José; Suanno, Marilza Vanessa Rosa; Suanno, João Henrique. (Org.). Complexidade, interdisciplinaridade e transdisciplinaridade na educação superior. 1ed.Goiânia: Espaço Acadêmico, 2015, v. 1, p. 93-112.

Viegas; SUANNO, J. H. Alfabetização na Escola Magsul: aprendendo a ler a palavra e o seu mundo. In: Pinho, Maria José; Suanno, Marilza Vanessa Rosa; Suannoo, João Henrique. (Org.). Projetos Criativos na Prática Pedagógica: cantar e encantar a aprendizagem. 1ed.Goiânia: Editora Espaço Acadêmico, 2015, v. 1, p. 139-157.

Viegas; experiências Inter e transdisciplinares na educação superior. In: Maria de Fátima Viegas Josgrilbert. (Org.). Experiências Interdisciplinares no Ensino Superior. 01ed.Ponta Porã-MS: EdFAMAG, 2015, v. 01, p. 11-25. 
SUANNO, J. H.; PAULA, M. V. G.; ARANTES, V. H. de P. O olhar transdisciplinar para a Educação Física Escolar. In: Maria José de Pinho; Marilza Vanessa Rosa Suanno; João Henrique Suanno. (Org.). Projetos criativos na prática pedagógica: cantar e encantar a aprendizagem. 1ed.Goiânia: Espaço Acadêmico, 2015, v. 1, p. 77-96.

\section{TRABALHOS COMPLETOS PUBLICADOS EM ANAIS DE CONGRESSOS}

SUANNO, João Henrique ; SUANNO, Marilza Vanessa Rosa . O Ser na Escola: suas aprendizagens, suas relações humanas e o desenvolvimento de valores. In: I Seminário da Rede Internacional de Escolas Criativas - I Seminário RIEC, 2014, Goiânia. Anais - I Seminário da Rede Internacional de Escolas Criativas. Goiânia - Goiás, 2014. v. 1. p. 653-667.

SUANNO, João Henrique; Estratégias Educativas Transdisciplinárias Desarolladas en el Colégio Logosófico de Goiânia. In: VI Fórum Internacional de Inovação e Criatividade - VI INCREA, 2014, Barcelona. VI Fórum Internacional de Inovação e Criatividade - VI INCREA. Barcelona: Círcolo Rojo, 2014. v. 1. p. 149-174.

VIEGAS; Emne Boufleur. Uma proposta interdisciplinar para o ensino fundamental. In: I Seminário RIEC, 2014, Goiânia. Anais do I RIEC. Goiânia: Editora UFG, 2014. p. 919-926.

VIEGAS; JOSGRILBERT, A. V. Transdisciplinaridade no ensino superior: uma proposta implantada. In: XII Congresso da Sociedade Portuguesa de Ciência da Educação, 2014, Vila Real. Atas do XII Congresso da Sociedade Portuguesa de Ciência da Educação. Vila Real: Universidade de Vila real e Alto Douro, 2014.

Viegas; JOSGRILBERT, A. V.; Emne Boufleur. História da Arte no Ensino Fundamental. In: XII Congresso da Sociedade Portuguesa de Ciência da Educação, 2014, Vila Real. Atas do XII Congresso da Sociedade Portuguesa de Ciência da Educação. Vila Real: Universidade de Vila Real e Alto Douro, 2014.

Viegas; JOSGRILBERT, A. V.; Valdes, Lysian Carolina. Um novo design de currículo para o curso superior: uma proposta interdisciplinar. In: $1^{\circ}$ Seminário RIEC, 2014, Goiânia. Anais do I RIEC. Goiânia: UFG, 2014. p. 893-9000.

CUNHA, R. C. A.; PAULA, M. V. G.; SUANNO, J. H. Mapa conceitual: da teoria de Ausubel à transdisciplinaridade. In: XII Congresso Nacional de Educação - EDUCERE, 2015, Curitiba. Mapa conceitual: da teoria de Ausubel à transdisciplinaridade, 2015. p. 5463-5480.

V. G.; MORAIS, S. A experiência estética na educação infantil: Para além de uma pedagogização. In: I Seminário da rede internacional de escolas criativas, 2014, Goiânia. I Seminário da rede internacional de escolas criativas, 2014. p. 74. 
PAULA, M. V.G.; A experiência da construção de um vídeo na Educação Física Escolar. In: I Seminário da rede internacional de escolas criativas, 2014, Goiânia. I Seminário da rede internacional de escolas criativas, 2014. p. 63-68.

\section{RESUMOS PUBLICADOS EM ANAIS DE CONGRESSOS}

JOSGRILBERT, Maria de Fátima Viegas; VALDEZ, M. E. A mudança da matriz curricular para criação de um curso de direito interdisciplinar. In: II CONJUR, 2013, Campo Grande. Anais do II CONUUR. Campo Grande: PROPP-UFMS, 2013. v. ÚNICO. p. 38-38.

PAULA, M. V.G.; Reflexão sobre a importância das tradições culturais populares na Educação Física Escolar. In: Simpósio Nacional Saberes e Expressões Culturais do Cerrado: Devoção e diversão nas tradições culturais populares, 2014, Pirenópolis. Simpósio Nacional Saberes e Expressões Culturais do Cerrado: Devoção e diversão nas tradições culturais populares. Goiânia: Kelps, 2014. p. 57-57.

A equipe do Estado de Goiás, coordenada pela Profa. Dra. Marilza Vanessa Rosa Suanno UEG/Campus Inhumas e UFG é composta por três alunos de iniciação cientifica, 1 graduando, 6 especializandos, 6 turmas de estágio supervisionado. Esta equipe já publicou 2 artigos completos publicados em periódicos, 10 livros publicados/organizados ou edições, 15 capítulos de livros publicados, 3 trabalhos completos publicados em anais de congressos e 1 tese de doutorado. As pesquisas centralizam-se na formação de professores, didática, educação superior, estágio supervisionado, educação básica, experiências educacionais criativas e inovadoras, transdisciplinaridade e multi/interculturalidade.

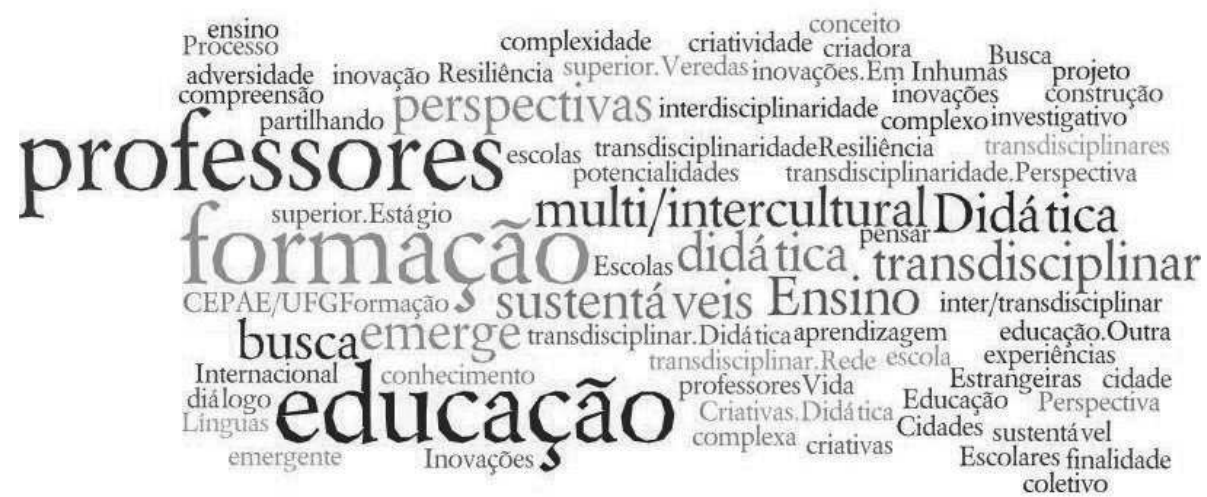




\section{ARTIGOS COMPLETOS PUBLICADOS EM PERIÓDICOS}

SUANNO, Marilza V. R.; MELO, K. A.; VIANA, C. P.; PESSONI, L. M. L; SANTOS, L. P.; REIS, M. B. F. Cidades sustentáveis e escolas sustentáveis: projeto coletivo Inter/ transdisciplinar. Desafios: Revista Interdisciplinar da UFT, v. 1, p. 186-206, 2014. LIMA, J. J. L; SUANNO, Marilza V. R. Perspectiva multi/intercultural e educação superior. Revelli: Revista de Educação, Linguagem e Literatura da UEG-Inhumas, v. 5, p. 110-118, 2013.

\section{LIVROS PUBLICADOS/ORGANIZADOS OU EDIÇÕES}

SUANNO, Marilza V. R.; SILVA, R. L. B. R. (Org.); FARIA, V. F. (Org.). Veredas Escolares: partilhando experiências criativas de ensino e aprendizagem do CEPAE/ UFG. 1. ed. Goiânia: América, 2014. v. 1. 358p.

SUANNO, Marilza V. R.; SUANNO, J. H. (Org.); FARIA, V. F. (Org.); ALMEIDA, M. J. O. F. (Org.); CONTI, C. (Org.); SILVA, A. H. (Org.). I Seminário da Rede Internacional de Escolas Criativas (ANAIS). 1. ed. Goiânia: CEPAE/UFG, 2014. v. 1.940 p.

LIBÂNEO, José Carlos (Org.); SUANNO, Marilza V. R. (Org.); LIMONTA, Sandra Valéria (Org.). A pesquisa sobre didática e práticas de ensino no Estado de Goiás: 10 anos de EDIPE Encontro Estadual de Didática e Práticas de Ensino. 1. ed. Goiânia: CEPED Publicações e Gráfica e Editora América, 2014. v. 1. 364p.

PINHO, Maria José de (Org.); SUANNO, Marilza V. R. (Org.); SUANNO, J. H. (Org.). Formação de professores e interdisciplinaridade: diálogo investigativo em construção. 1. ed. Goiânia: América, 2014. v. 1. 456p.

SUANNO, Marilza V. R.; SUANNO, J. H. (Org.); SANTOS, Akiko (Org.). Didática e formação de professores: complexidade e transdisciplinaridade. 1. ed. Porto Alegre: Sulina, 2013. v. 1. 352p.

SUANNO, Marilza V. R.; MAURA PUJOL, M. A. (Org.); DITTRICH, M. G. (Org.). Resiliência, criatividade e inovação: potencialidades transdisciplinares na Educação. 1. ed. Anápolis: Editora UEG, 2013. v. 1. 268p.

PUJOL MAURA, Maria Antonia (Org.); RAJADELL PUIGGROS, Núria (Org.); SUANNO, Marilza V. R. (Org.). Didáctica y Formación: Una mirada transdisciplinar. 1. ed. Círculo Rojo, 2013. v. 1. 304p.

SUANNO, Marilza V. R.; Didáctica y Formación: Una mirada transdisciplinar. 1. ed. Círculo Rojo, 2013. v. 1. 22p.

LIBÂNEO, José Carlos (Org.); SUANNO, Marilza V. R. (Org.); LIMONTA, Sandra Valéria (Org.); EVANGElistA, O. (Org.); TIBAlli, Elianda F. A. (Org.); 
PIMENTA, S. G. (Org.); MOREIRA, A. F. B. (Org.); OLIVEIRA, M. R. N. S. (Org.); ANASTASIOU, L. G. C. (Org.); SILVA, K. A. C. P. C. (Org.); TOSCHI, Mirza Seabra (Org.); ALONSO, K. M. (Org.). Qualidade da escola pública; políticas educacionais, didática e formação de professores. 1. ed. Goiânia: CEPED Publicações; América e Kelps, 2013. v. 1. 229p.

SUANNO, Marilza V. R.; RAJADELL PUIGGROS, Núria (Org.). Didática e formação de professores: perspectivas e inovações. 1. ed. Goiânia: Puc Goiás/América, 2012. v. $1.416 \mathrm{p}$.

\section{CAPÍTULOS DE LIVROS PUBLICADOS}

SUANNO, Marilza V.R.; Em busca da compreensão do conceito de transdisciplinaridade. In: MORAES, Maria Cândida e SUANNO, João Henrique. (Org.). O pensar complexo na educação - sustentabilidade, transdisciplinaridade e criatividade. 1ed. São Paulo: WAK, 2014, v. 1, p. 99-126.

DUARTE, D. C. L. L.; SUANNO, Marilza V. R. Universidade e políticas públicas de cotas raciais. In: Marlene Barbosa de Freitas Reis. (Org.). Docência Universitária 2 -Práticas interdisciplinares no ensino superior. 1ed.Anápolis: Editora UEG, 2014, v. 1, p. 83-98.

LIMA, J. J. L.; SUANNO, Marilza V. R. Perspectiva multi/intercultural e educação superior. In: Marlene Barbosa de Freitas Reis. (Org.). Docência Universitária 2 -Práticas interdisciplinares no ensino superior. 1ed.Anápolis: Editora da UEG Universidade Estadual de Goiás, 2014, v. 1, p. 153-164.

SUANNO, Marilza V. R.; Estágio transdisciplinar na formação de professores. In: Edson Schroeder e Vera Lúcia de Souza e Silva (orgs.). (Org.). Novos talentos processos educativos em ecoformação. 1ed.Blumenau: Lebere, 2014, v. 1, p. 205214.

SUANNO, Marilza V. R.; Vida e conhecimento: emerge uma didática transdisciplinar. In: José Carlos Libâneo, Marilza Vanessa Rosa Suanno, Sandra Valéria Limonta. (Org.). A pesquisa sobre didática e práticas de ensino no Estado de Goiás - 10 anos de EDIPE. 1ed.Goiânia: Kelps, 2014, v. 1, p. 332-345.

SUANNO, Marilza V. R.; TORRE, Saturnino De La. SUANNO, J. H. Rede Internacional de Escolas Criativas. In: Maria José de Pinho; Marilza Vanessa Rosa Suanno; João Henrique Suanno. (Org.). Formação de professores e interdisciplinaridade: diálogo investigativo em construção. 1ed.Goiânia: América, 2014, v. 1, p. 15-32.

SUANNO, Marilza V. R.; Didática transdisciplinar emergente. In: Akiko Santos; João Henrique Suanno; Marilza Vanessa Rosa Suanno. (Org.). Didática e formação de 
professores: complexidade e transdisciplinaridade. 1ed.Porto Alegre: Sulina, 2013, v. 1, p. 23-50.

SUANNO, Marilza V. R.; LIMONTA, Sandra Valéria; SILVA, C. C. Resiliência, adversidade criadora e educação. In: SUANNO, DITTRICh e MAURA PUJOL. (Org.). Resiliência, criatividade e inovação: potencialidades transdisciplinares na Educação. 1ed.Anápolis: Editora da UEG - Universidade Estadual de Goiás, 2013, v. 1, p. 54-68.

SUANNO, Marilza V. R.; Outra finalidade para a educação: emerge uma didática complexa e transdisciplinar. In: Marlene ZWIEREWICZ. (Org.). Criatividade e inovação no ensino superior: experiências de ensino, pesquisa e extensão latinoamericanas e europeias em debate. 1ed.João Pessoa: Editora da Universidade Federal da Paraíba, 2013, v. 1, p. 15-30.

SUANNO, Marilza V. R.; TOSCHI, Mirza Seabra; SOUZA; ANDERI, Eliane; SILVA, D. C. S. E.; PEREIRA, A. L. Profesión maestro: sabores y disabores del profesional docente en el interior de brasil. In: Marilza Suanno. (Org.). Formación del profesorado: perspectivas y reflexiones (prelo). 49ed.Sevilla/Espanha: Circulo Rojo, 2013, v., p. 34-.

SUANNO, Marilza V. R.; Reorganización del trabajo docente en la educación superior: innovaciones didácticas. In: Maria Antònia Pujol; Núria Rajadell e Marilza Vanessa Rosa Suanno. (Org.). Didáctica y formación - una mirada transdisciplinar. 1ed. Sevilla/Espanha: Circulo Rojo, 2013, v., p. 183-214.

SUANNO, Marilza V. R.; La educación superior y los estudios de postgrado:lineas estratégicas de actuación para el desarrollo de Brasil. In: Marilza Suanno. (Org.). Formación del profesorado: perspectivas y reflexiones (prelo). 1ed.Sevilla/Espanha: Circulo Rojo, 2013, v., p. 1-15.

SUANNO, Marilza V. R.; PINHO, Maria José de. Formação inicial do professor universitário no estágio supervisionado na educação a distância. In: Wagner Rodrigues Silva. (Org.). Letramento do Professor em Formação Inicial: Interdisciplinaridade no Estágio Supervisionado da Licenciatura. 1ed.Campinas, S.P.: Pontes Editores, 2012, v. 1, p. 209-230.

SUANNO, Marilza V. R.; Reorganização do trabalho docente na educação superior: inovações didáticas. In: Marilza Suanno e Núria Rajadell. (Org.). Didática e formação de professores: perspectivas e inovações. 1ed.Goiânia - GO: PUC Goiás e CEPED Publicações, 2012, v. 1, p. 211-240.

BARBOSA, Thierry Augusto Ferreira. SUANNO, Marilza Vanessa Rosa. Ensino de Línguas Estrangeiras: Em Busca de Inovações no Processo de Ensino. Parceria in 
PINHO, Maria Jose. SUANNO,Marilza Vanessa Rosa. SUANNO, João Henrique. Projetos criativos na Prática Pedagógica Cantar e encantar a aprendizagem. Espaço Academico,2015 p.231 a 238

\section{TRABALHOS COMPLETOS PUBLICADOS EM ANAIS DE CONGRESSOS}

COSTA, Ana Carolina Fernandes. SUANNO, Marilza Vanessa Rosa. O pensar complexo na educação: Em busca de uma cidade e uma escola sustentável. Inhumas, 2015. EDUCERE,2015

BARBOSA, Thierry Augusto Ferreira. SUANNO, Marilza Vanessa Rosa. Indícios de Criatividade e Inovação no Processo de Ensino Aprendizagem Na Escola Letras De Alfenim - Inhumas.

JANUARIO, Wanderson Cândido. SUANNO, Marilza Vanessa Rosa. Estágio Curricular Transdisciplinar: Pensar complexo o metatema água, mudar as atitudes e ampliar a consciência, Inhumas ,2015. EDUCERE, 2015.

A equipe do Estado do Ceará, coordenada Profa. Dra. Patrícia Limaverde Universidade Estadual do Ceará - UECE, publicou sobre a Escola Vila, 1 artigo completo publicado em periódicos; 1 livro publicado/organizado ou edições; 3 capítulos de livros publicados; 2 trabalhos completos publicados em anais de congressos e 2 resumos publicados em anais de congresso e 1 tese de doutorado, trabalhos sobre escola, currículo e transdisciplinaridade, que fundamentam e analisam a formação de professores e o trabalho pedagógico desenvolvido na Escola Vila, em Fortaleza/Ceará.

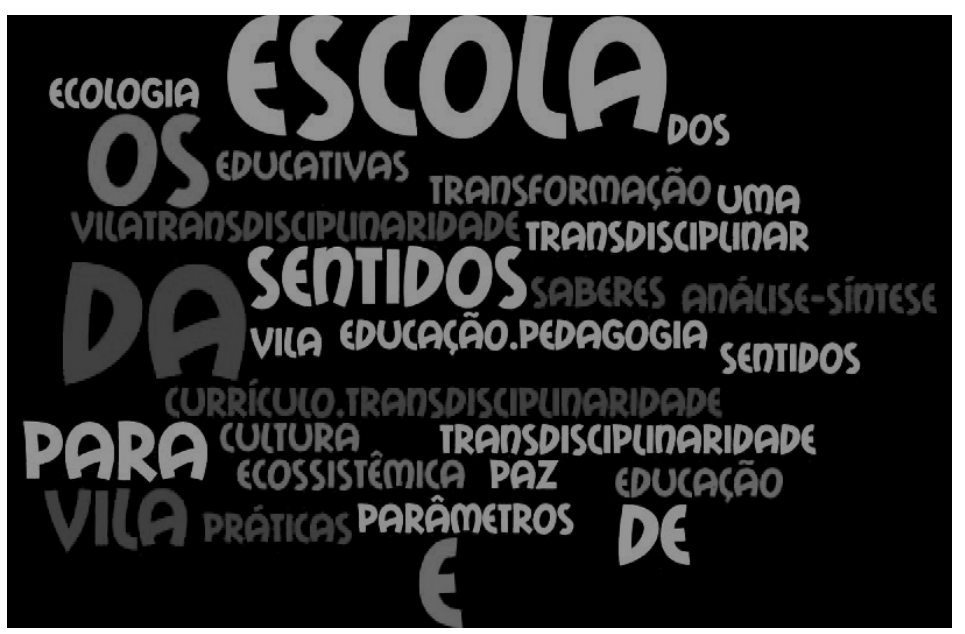




\section{ARTIGOS COMPLETOS PUBLICADOS EM PERIÓDICOS}

Moraes, M.C. ; VIEIRA, A. J. H. ; SCHIMIDT NETO, A. ; HESSEL, A. M. G. ; SILVA, A. P. C. E. ; SANTOS, C. G. ; SUANNO, J. H. ; BATALLOSO, J. M. ; PESCE, L. M. ; ALVES, M. D. F. ; HOLANDA, M. J. B. ; SUANNO, M. V. R. ; MACHADO, Michelle Jordão ; RIBEIRO, O. C. ; LIMAVERDE, P. ; SCHERRE, P. P. ; MENDES, P. C. ; GALASSO, R. ; ARNT, R.M. ; SCHECHTMAN, S. . Editorial - Dossiê Ecotransd: Ecologia dos Saberes, Transdisciplinaridade e Educação. Revista Terceiro Incluído, v. 5, p. 1-6, 2015.

\section{LIVROS PUBLICADOS/ORGANIZADOS OU EDIÇÕES}

Pedagogia Ecossistêmica: educação transdisciplinar da Escola Vila. 1. ed. Fortaleza: Editora da Vila, 2015. v. 1. 256p.

\section{CAPÍTULOS DE LIVROS PUBLICADOS}

NASCIMENTO, P. L.; LIMAVERDE, Morena. Os Sentidos da Escola VILA. In: PINHO, M. J.; SUANNO, M. V. R.; SUANNO, J. H. (Org.). Projetos criativos na prática pedagógica: cantar e encantar a aprendizagem. 1ed.Goiânia: Editora Espaço Acadêmico, 2015, v., p. 157-170.

NASCIMENTO, P. L.; MACHADO, Michelle Jordão; LEITE, Deliene Lopes. Os operadores cognitivos do pensar complexo na docência universitária: possibilidades e desafios. In: MORAES, Maria Cândida; SUANNO, João Henrique. (Org.). O pensar complexo na Educação: sustentabilidade, transdisciplinaridade e criatividade. 1ed.São Paulo: WAK, 2014, v., p. 211-.

NASCIMENTO, P. L.; Parâmetros para análise-síntese de práticas educativas. In: SUANNO, Marilza; DITTRICH, Maria Glória; MAURA, Maria Antònia. (Org.). Resiliência, Criatividade e Inovação: potencialidades transdisciplinares em educação. 1ed.Goiânia: UEG/ Ed. América, 2013, v., p. 75-99.

TRABALHOS COMPLETOS PUBLICADOS EM ANAIS DE CONGRESSOS

NASCIMENTO, P. L.; Os sentidos da Escola Vila. In: I SEMINÁRIO DA REDE INTERNACIONAL DE ESCOLAS CRIATIVAS, 2014, Goiânia. I Seminário da Rede Internacional de Escolas Criativas - ANAIS. Goiânia: UFG, 2014. v. 1. p. 715-722.

NASCIMENTO, P. L.; Transdisciplinaridade e Currículo. In: I Seminário Internacional Transdisciplinaridade e Complexidade da Consciência Humana, 2014, Horizonte. I Seminário Internacional Transdisciplinaridade e Complexidade da Consciência Humana, 2014. 


\section{RESUMOS PUBLICADOS EM ANAIS DE CONGRESSOS}

NASCIMENTO, P. L.; Transdisciplinaridade e transformação para uma cultura de paz. In: XVII ENDIPE Encontro Nacional de Didática e Prática de Ensino, 2014, Fortaleza. XVII ENDIPE Encontro Nacional de Didática e Prática de Ensino. Fortaleza: Editora UECE, 2014.

ARNT, R.; SUANNO, M. V. R.; LIMAVERDE, P.; HOLANDA, M. J. B. Transdisciplinaridade em Educação: transformação social e cultura de paz. In: XVII ENDIPE Encontro Nacional de Didática e Prática de Ensino, 2014, Fortaleza. XVII ENDIPE Encontro Nacional de Didática e Prática de Ensino. Fortaleza: Editora UECE, 2014.

A equipe da Universidade do Vale do Itajaí - UNIVALI, em Santa Catarina, coordenado pela Profa. Maria Glória Dittrich publicou 1 livro publicado/organizado ou edições; 3 capítulos de livros publicados; 2 trabalhos completos publicados em anais de congressos e 2 resumos publicados em anais de congresso. As pesquisas na área da Saúde, Políticas Públicas, Ecoformação e educação transdisciplinar.

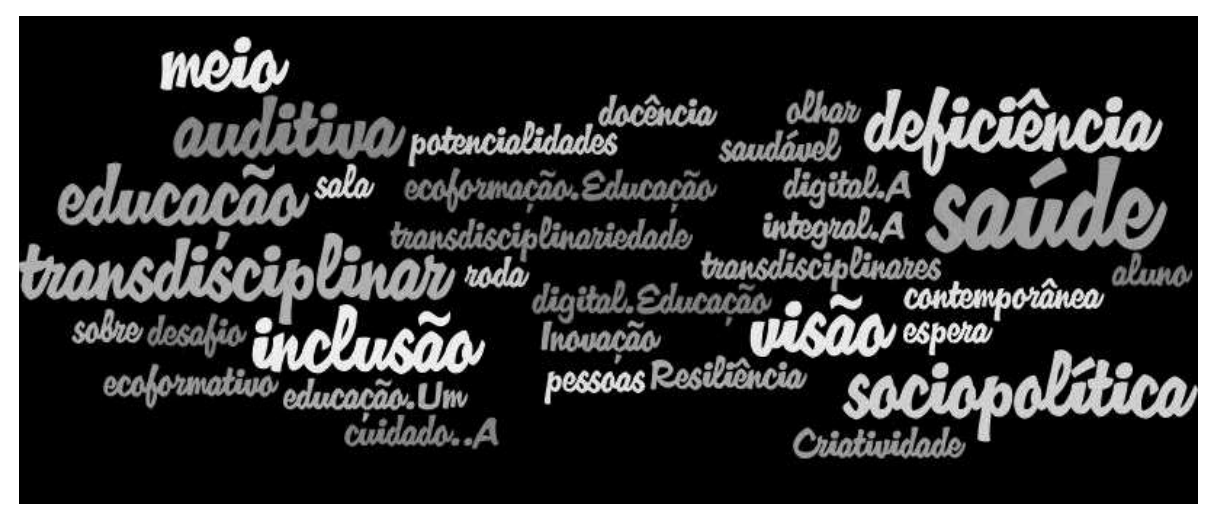

\section{LIVROS PUBLICADOS/ORGANIZADOS OU EDIÇÕES}

SUANNO,Marilza Vanessa Rosa (Org.) ; DITTRICH, M. G. (Org.) . Resiliência, Criatividade e Inovação: potencialidades transdisciplinares na educação. 1. ed. GAIANIA: UEG/Ed. América, 2013. 264p. 


\section{CAPÍTULOS DE LIVROS PUBLICADOS}

DITTRICH, M. G.; ESPINDOLA, Karla Simoni da Silva; KOEFENDER, M. Um olhar transdisciplinar e ecoformativo para a educação à saúde integral. In: Marilza Vanessa Rosa Suanno, Maria Glória Dittrich, Maria Antònia Pujol Maura. (Org.). Resiliência, Criatividade e Inovação: potencialidades transdisciplinares na educação. 1ed.Goiania: UEG/Ed. América, 2013, v., p. 9-264.

DITTRICH, M. G.; MELLER, GIORGI, M. D. M. A roda da saúde: a sala de espera numa visão transdisciplinar do cuidado. In: Berenice Rocha Zabbot Garcia; Gladis Luisa Baptista. (Org.). Saúde: a contribuição da extensão universitária. 255ed. Joinvile: Editora da UNIVILLE, 2013, v. 1, p. 7-193.

TORTORELlO, G. A visão do aluno com deficiência auditiva sobre inclusão sociopolítica por meio digital. In: Marilza Vanessa Rosa Suanno, Maria Glória Dittrich, Maria Antònia Pujol Maura. (Org.). Resiliência, Criatividade e Inovação: potencialidades transdisciplinares na educação. 1ed.Goiânia: UEG/Ed. América, 2013, v., p. 245-260.

\section{TRABALHOS COMPLETOS PUBLICADOS EM ANAIS DE CONGRESSOS}

DITTRICH, M. G.; ESPINDOLA, K. S.; KOEFENDER, M. Educação em saúde: transdisciplinariedade e ecoformação. In: IV Forum Internacional Innovación y creatividad, 2012, Barcelona. Adversidad y escuelas creativas. Barcelona: Universidade de Barcelona, 2012. p. 1-8.

DITTRICH, M. G.; TORTORELLO, Educação e inclusão sociopolítica de pessoas com deficiência auditiva por meio digital. In: IV Forum Internacional Innovación y Creatividad, 2012, barcelona. Adversidad Y Escuelas Creativas. Barceloa: Universidade de Barcelona, 2012. p. 1-13.

\section{RESUMOS EXPANDIDOS PUBLICADOS EM ANAIS DE CONGRESSOS}

DITTRICH, M. G.; A docência saudável: um desafio para a educação contemporânea. In: IV Fórum Internacional Innovación y creatividad, 2012, Barcelona. Adversidad y Escuelas Creativas. Barceloa: Universidade de Barcelona, 2012. p. 1-4.

Assim totalizando o RIEC/Brasil possui 34 artigos completos publicados em periódicos; 30 livros publicados/ organizados ou edições; 70 capítulos de livros publicados; 45 trabalhos completos publicados em anais de congressos; 19 resumos publicados em anais de congressos; 5 outras produções bibliográficas e 1 artigo aceito para publicação. É composto por 7 coordenadores de grupos de 
pesquisa, 11 alunos de iniciação cientifica, 7 graduandos, 8 especializandos, 18 mestrandos, 3 doutorandos, 1 pós-doutoranda, 6 turmas de estágio supervisionado. Tendo a RIEC/Brasil pesquisado, entre 2012-2015, as escolas e os projetos pedagógicos da:

- Escola Vila - Fortaleza/Ceará

- Escola de Tempo Integral Daniel Batista - Palmas/Tocantins

- Colégio Logosófico de Goiânia - Goiânia/Goiás

- Centro de Ensino e Pesquisa Aplicada à Educação - CEPAE, da Universidade Federal de Goiás - UFG - Goiânia/Goiás

- Escola Estadual de Tempo Integral João Lobo Filho - Inhumas/Goiás

- Escola Letras de Alfenim - Cidade de Goiás/Goiás

- Estágio Supervisionado do curso de Pedagogia, nos anos iniciais do ensino fundamental, da UEG - Inhumas/Goiás e FE/UFG - Goiânia/Goiás

- Bacharelado em direito da Faculdade de Educação Ciências e Letras - MAGSUL - Ponta Porã/Mato Grosso do Sul

- Escola Municipal de Ensino Fundamental Amélia de Souza Silva - Balneário Rincão/Santa Catarina

- Projeto Urussanga - Vira Criança - Urussanga/Santa Catarina

- Escola Básica Municipal Visconde de Taunay - Blumenau/Santa Catarina

\section{Conclusão}

Este artigo teve por objetivo produzir um mapeamento das pesquisas e das publicações brasileiras vinculadas a Rede Internacional de Escolas Criativas - RIEC, produzidas entre 2012 e 2015. Estas pesquisas identificam professores, escolas, comunidades e trabalhos docentes com indícios de criatividade, de inovação, de auto-ecoformação, com potencial transformador de pessoas, de projetos e de realidades.

\section{Referências}

MALLART, J. Ecoformação para a escola do século XXI. In M. Zwierewicz \& S. De La Torre (Orgs.), Uma escola para o século XXI - Escolas criativas e resiliência na educação (pp.29-41), Florianópolis: Insular, 2009. 
MORIN, E. Introdução ao Pensamento Complexo. Lisboa. Instituto Piaget, 1991.

Os sete saberes necessários à educação do futuro. Tradução de Catarina Eleonora F. da Silva e Jeanne Sawaya; revisão técnica de Edgard de Assis Carvalho. 2. ed. São Paulo: Cortez; Brasília, DF: UNESCO, 2000.

PINHO, M. J. de. Projetos criativos na prática pedagógica: cantar e encantar a aprendizagem. - Maria José de Pinho, Marilza Vanessa Rosa Suanno, João Henrique Suanno (orgs.). - Goiânia: / Editora Espaço Acadêmico, 2015.

PINHO, M. J. de. Complexidade, interdisciplinaridade e transdisciplinaridade na educação superior / Maria José de Pinho, Marilza Vanessa Rosa Suanno, João Henrique Suanno e Elzimar Pereira Nascimento Ferraz (orgs.). - Goiânia: / Editora Espaço Acadêmico, 2015.

SANTOS, A. Didática sob a ótica do pensamento complexo. Editora Sulina, Porto Alegre, 2003.

SILVA, A. T. R. da. Ecoformação: reflexões para uma pedagogia ambiental Desenvolvimento e Meio Ambiente, n. 18, Editora UFPR, jul./dez. 2008, p. 95-104.

SUANNO, M. V. R. Em busca da compreensão do conceito de transdisciplinaridade. In: MORAES, Maria Cândida e SUANNO, João Henrique. O pensar complexo na educação: sustentabilidade, transdisciplinaridade e criatividade. Rio de Janeiro: WAK, 2013.

SUANNO, M. V. R. Outra finalidade para a educação: emerge uma didática complexa e transdisciplinar. In: ZWIEREWICZ, M. Criatividade e inovação no ensino superior: experiências latino-americanas e europeias em foco. Blumenau: Nova Letra, 2013.

SUANNO, M. V. R.; TORRE, S. de la e SUANNO, J. H. Rede Internacional de Escolas Criativas. In: PINHO, M. J.; SUANNO, M. V. R. e SUANNO, J. H.. Formação de professores e interdisciplinaridade: diálogo investigativo em construção. Goiânia: América, 2014. p. 15-33.

Recebido em: 10 abril 2016.

Aceito em: 20 abril 2016. 